\title{
Cdk5-Mediated Phosphorylation of Axin Directs Axon Formation during Cerebral Cortex Development
}

\author{
Wei-Qun Fang, ${ }^{1,2,3}$ Jacque P. K. Ip, ${ }^{1,2,3}$ Rui Li, ${ }^{1,2,3}$ Yu Pong Ng, ${ }^{1,2,3}$ Sheng-Cai Lin, ${ }^{4}$ Yu Chen, ${ }^{1,2,3}$ Amy K. Y. Fu, ${ }^{1,2,3}$ \\ and Nancy Y. Ip ${ }^{1,2,3}$ \\ ${ }^{1}$ Division of Life Science, ${ }^{2}$ Molecular Neuroscience Center, and ${ }^{3}$ State Key Laboratory of Molecular Neuroscience, The Hong Kong University of Science and \\ Technology, Clear Water Bay, Hong Kong, China, and ${ }^{4}$ School of Life Sciences, Xiamen University, Fujian 361005, China
}

\begin{abstract}
Axon formation is critical for the establishment of connections between neurons, which is a prerequisite for the development of neural circuitry. Kinases such as cyclin-dependent kinase 5 (Cdk5) and glycogen synthase kinase-3 $\beta$ (GSK-3 $\beta$ ), have been implicated to regulate axon outgrowth. Nonetheless, the in vivo roles of these kinases in axon development and the underlying signaling mechanisms remain essentially unknown. We report here that $\mathrm{Cdk} 5$ is important for axon formation in mouse cerebral cortex through regulating the functions of axis inhibitor (Axin), a scaffold protein of the canonical Wnt pathway. Knockdown of Axin in utero abolishes the formation and projection of axons. Importantly, Axin is phosphorylated by Cdk5, and this phosphorylation facilitates the interaction of Axin with GSK-3 $\beta$, resulting in inhibition of GSK-3 $\beta$ activity and dephosphorylation of its substrate collapsin response mediator protein-2 (CRMP2 ), a microtubule-associated protein. Specifically, both phosphorylation of Axin and its interaction with GSK-3 $\beta$ are critically required for axon formation in mouse cortex development. Together, our findings reveal a new regulatory mechanism of axon formation through Cdk5-dependent phosphorylation of Axin.
\end{abstract}

\section{Introduction}

Precise information processing in the brain requires correct positioning of neurons and proper neuronal connectivity. After migration to the cortical plate $(\mathrm{CP})$, neocortical neurons extend axons, which project over long distances to intracortical and subcortical areas for coordination of information processing. Axon formation therefore plays critical roles in maintaining the functional integrity of the cerebral cortex. Formation and extension of axon is tightly regulated by coordinated changes of the actin cytoskeleton and microtubule network (Bradke and Dotti, 1999; Witte et al., 2008). In particular, stabilization of microtubules is both necessary and sufficient to induce axon formation (Witte et al., 2008). Microtubule stabilization is controlled by the activities of microtubule-associated proteins (MAPs), which are regulated by their phosphorylation status (Mandell and Banker, 1995; Witte and Bradke, 2008; Conde and Cáceres, 2009). Kinases, such as LKB1 and Par1-related SAD kinases, are essential for the po-

Received June 20, 2011; revised July 25, 2011; accepted July 28, 2011.

Author contributions: W.-Q.F., A.K.Y.F., and N.Y.I. designed research; W.-Q.F., R.L., and Y.P.N. performed research; W.-Q.F., J.P.K.I., S.-C.L., and Y.C. contributed unpublished reagents/analytic tools; W.-Q.F., J.P.K.I., R.L., Y.P.N., S.-C.L., Y.C., A.K.Y.F., and N.Y.I. analyzed data; W.-Q.F., A.K.Y.F., and N.Y.I. wrote the paper.

This study was supported in part by the Research Grants Council of Hong Kong (The Hong Kong University of Science and Technology Grants 661007, 660808, 661109, 660110, and 1/06C), the Area of Excellence Scheme of the University Grants Committee (Grant AoE/B-15/01), and the Hong Kong Jockey Club. N.Y.I. was a recipient of the Croucher Foundation Senior Research Fellowship. We are grateful to Prof. Yukiko Gotoh for the in utero electroporation technique and pCAGI2G construct, and Prof. Kozo Kaibuchi for p-CRMP-2 antibody. We also thank Drs. Kwok-On Lai and Zelda Cheung for critical reading of this manuscript, Dr. Wing-Yu Fu, Hayley W. Tsang, Ying Dai, and Cara W. Kwong for their excellent technical assistance, and members of the Ip laboratory for helpful discussions.

Correspondence should be addressed to either Prof. Nancy Y. Ip or Dr. Amy K. Y. Fu, Division of Life Science, The Hong Kong University of Science and Technology, Clear Water Bay, Hong Kong, China. E-mail: boamy@ust.hk; boip@ust.hk.

DOI:10.1523/JNEUROSCI.3120-11.2011

Copyright $\odot 2011$ the authors $\quad 0270-6474 / 11 / 3113613-12 \$ 15.00 / 0$ larization of neurons and axon formation in mouse cerebral cortex through precise regulation of the phosphorylation status of MAPs and thus microtubule stability (Kishi et al., 2005; Barnes et al., 2007; Shelly et al., 2007).

The kinase glycogen synthase kinase- $3 \beta$ (GSK-3 $\beta$ ) has been characterized as a negative regulator of axon formation in cultured neurons through direct phosphorylation of MAPs and destabilization of microtubules (Jiang et al., 2005). Interestingly, GSK- $3 \beta$ is negatively regulated by another kinase cyclin-dependent kinase 5 (Cdk5), the activity of which is critical for neuronal polarization and axon development (Paglini et al., 1998; Kwon et al., 1999; Connell-Crowley et al., 2000; Morfini et al., 2004; Engmann and Giese, 2009). Nonetheless, how Cdk5 regulates axon development is unclear. Because inhibition of Cdk5 in neurons leads to dephosphorylation and enhanced activation of GSK-3 $\beta$, it is tempting to speculate that Cdk5 may regulate axon formation through modulation of GSK-3 $\beta$ activity. Moreover, phosphorylation of a myriad of MAPs, including Tau, MAP2, and MAP1B by Cdk5 (Smith and Tsai, 2002) suggests that the kinase regulates axon development through modulation of microtubule dynamics.

Axis inhibitor (Axin), a scaffold protein in the canonical Wnt signaling (Kikuchi, 1999), is well characterized to inhibit axis formation during early development of the central nervous system in zebrafish and mouse embryos (Perry et al., 1995; Heisenberg et al., 2001; Carl et al., 2007; Rui et al., 2007). Nonetheless, the in vivo role of Axin in neuronal development has remained essentially unknown. Axin stabilizes microtubule network via its interaction with GSK-3 $\beta$ (Ciani et al., 2004), implicating a role of Axin in the regulation of GSK- $3 \beta$ during axon formation. Thus, it is of interest to study whether and how Axin functions as a scaffold protein to coordinate the regulatory actions of its interacting proteins during axon formation. 
In this study, we show that phosphorylation of Axin by Cdk5 directs axon formation during development of the mouse cerebral cortex through enhancing interaction of Axin and GSK-3 $\beta$. Silencing of Axin in utero abolishes the formation and projection of axons in the developing cortex. Importantly, Cdk5 phosphorylates Axin in vivo, and the phosphorylation of Axin leads to inactivation of GSK-3 $\beta$ and thereby regulates the GSK-3 $\beta /$ collapsin response mediator protein-2 (CRMP-2)-dependent stabilization of microtubules. Collectively, our findings reveal that Cdk5-dependent phosphorylation of Axin directs axon formation through GSK-3 $\beta$-dependent microtubule reorganization.

\section{Materials and Methods}

Chemicals and antibodies. Rhodamine-conjugated phalloidin, CellTracker Orange CMRA, TO-PRO3 Iodide (642/661), recombinant Cdk5/p25 complex, Lipofectamine, and the Plus Reagent were purchased from Invitrogen. The QuikChange II XL Site-Directed Mutagenesis kit was from Stratagene. The nuclear/cytosol fractionation kit was from BioVision. The inhibitors roscovitine (Ros) and wortmannin (Wort) were purchased from Calbiochem. Monoclonal antibodies used for immunostaining or immunoblotting included the following: anti-MAP2, anti- $\alpha$-tubulin, anti- $\beta$-tubulin III (TuJ1), and anti-acetylated $\alpha$-tubulin (Ace- $\alpha$-tub) from Sigma; anti-Tau-1, anti-MAP2, and anti- $\beta$-actin from Millipore Bioscience Research Reagents; anti-GSK-3 $\beta$ from BD Transduction Laboratory and from Millipore; anti-Cdk5 (DC-17) from Santa Cruz Biotechnology; anti-CRMP-2 from IBL; anti-TAG1 (4D7) from Developmental Studies Hybridoma Bank; and anti-smi-312 from Covance. Polyclonal antibodies used included the following: anti-Axin from Sigma; anti-MAP2 from Millipore Bioscience Research Reagents; antiGSK-3 $\beta$, anti-p-GSK-3 $\beta$ (Ser9), anti-aPKC, anti-p-aPKC (Thr410/403), anti-Akt, anti-p-Akt (Ser473), anti-p35/p25 (C64B10), and anti-Ser/ Thr-Pro from Cell Signaling Technology; anti-synapsin I from Calbiochem; and anti-GFP from MBL; anti-Cdk5 (c-8) from Santa Cruz Biotechnology. Alexa Fluor 488-conjugated anti-GFP and Alexa Fluor 488-, 546-, 647-conjugated secondary antibodies were purchased from Invitrogen. Rabbit anti-p-CRMP-2 (Thr514) was kindly provided by Dr. Kozo Kaibuchi (Nagoya University Graduate School of Medicine, Nagoya, Japan).

The phospho-specific antibody for Axin at p-Thr485 was custom generated by immunization of the rabbit with phosphopeptide of Axin [HVQRVMRpTPGCQSPGPGHC (amino acids 478-495) conjugated to a carrier protein; Bio-Synthesis] and affinity purified using the SulfoLink Kit (Pierce Biotechnology). In brief, the serum from the immunized rabbit was run over the Sulfolink column with nonphosphorylated peptide (HVQRVMRTPGCQSPGPGHC), and then the phospho-specific antibody in the flow-through was affinity absorbed to the phosphorylated peptide coupled to the Sulfolink column.

shRNA and cDNA expression constructs. Full-length mouse Axin1 cDNA was subcloned into pcDNA3 and pCAGI2G vectors (kindly provided by Dr. Yukiko Gotoh, University of Tokyo, Tokyo, Japan). To generate pSUPER-Axin shRNA constructs, double-strained oligonucleotides encoding Axin shRNA (shAxin) were subcloned into BglII- and HindIII-digested pSUPER vector. The shRNA targets the mRNA sequences of both rat and mouse Axin1. The target sequence is $5^{\prime}$-AGUA CAUCCUGGAUAGCAA-3'. The shRNA-resistant Axin expression construct was generated by introducing four silent mutations into the cDNA sequence that is targeted by shAxin, without changing the amino acid sequence. All site-directed mutagenesis were performed using the QuikChange II XL Site-Directed Mutagenesis kit. Axin ${ }^{\text {Res_WT, Axin }}{ }^{\text {Res }}$

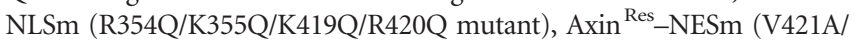
M423A mutant), Axin ${ }^{\text {Res }}-\mathrm{T} 485 \mathrm{~A}$, and Axin ${ }^{\text {Res }}$-L392P constructs were generated by subcloning the sequences encoding Axin ${ }^{\text {Res_WT, Axin }}{ }^{\text {Res }}$ NLSm, Axin ${ }^{\text {Res_-NESm, Axin }}{ }^{\text {Res-T485A, and Axin }}{ }^{\text {Res }}$-L392P into EcoRV digested pCAGI2G vector.

Coimmunoprecipitation analysis. Proteins of rat brains, cultured neurons, or HEK 293T cells were extracted by lysis buffer (50 mM Tris-Cl, $\mathrm{pH}$ 8.0, $150 \mathrm{~mm} \mathrm{NaCl}, 50 \mathrm{~mm} \mathrm{NaF}, 10 \%$ glycerol, 2 mм EGTA, and $0.5 \%$ NP-40) with various protease inhibitors (1 $\mathrm{mm}$ phenylmethylsulfonyl fluoride, $5 \mathrm{~mm}$ benzamidine, $10 \mu \mathrm{g} / \mathrm{ml}$ leupeptin, $10 \mu \mathrm{g} / \mathrm{ml}$ aprotinin, 10 $\mu \mathrm{g} / \mathrm{ml}$ trypsin inhibitor, $2 \mu \mathrm{g} / \mathrm{ml}$ antipain, and $1 \mathrm{~mm}$ sodium orthovanadate) and then centrifuged at $13,200 \mathrm{rpm}$ at $4^{\circ} \mathrm{C}$ for $30 \mathrm{~min}$. The lysates $(\sim 1-2 \mathrm{mg})$ were incubated with corresponding antibodies at $4^{\circ} \mathrm{C}$ for $3 \mathrm{~h}$, followed by incubation with protein $\mathrm{G}$ Sepharose at $4^{\circ} \mathrm{C}$ for $1 \mathrm{~h}$. The coimmunoprecipitates were then washed three times with lysis buffer, eluted by boiling in SDS-PAGE sample buffer, and then subjected to Western blotting analysis with the indicated antibodies.

In vitro phosphorylation assay. Wild-type (WT) and T485A mutant of Axin were overexpressed in HEK 293T cells. For in vitro phosphorylation assay, Axin protein immunoprecipitated from HEK $293 \mathrm{~T}$ cells was incubated with reconstituted Cdk5/p25 for $30 \mathrm{~min}$ at $30^{\circ} \mathrm{C}$ in $50 \mu \mathrm{l}$ of kinase buffer. For calf intestinal phosphatase (CIP) treatment, after phosphorylation reaction, the mixture was treated with CIP for an additional 30 $\min$ at $30^{\circ} \mathrm{C}$. The phosphorylated protein was then separated on $7.5 \%$ SDS-PAGE and then blotted with our custom phospho-specific antibody against Thr485 of Axin.

In utero electroporation. In utero electroporation was performed as described previously (Saito, 2006) with minor modifications. Briefly, timed-pregnant female mice (E13.5 or E14.5) were anesthetized with pentobarbital $(5 \mathrm{mg} / \mathrm{ml})$ and placed on the heat plate at $38^{\circ} \mathrm{C}$. Embryos were lifted using ring forceps through a $\sim 1.5 \mathrm{~cm}$ incision in the ventral peritoneum and placed on humidified gauze pads. Plasmid DNA solution $(2-5 \mu \mathrm{g} / \mu \mathrm{l}$, prepared using Qiagen plasmid maxi kits) mixed with $0.05 \%$ Fast Green was injected into the brain lateral ventricles using mouth-controlled micropipette. Electrical pulses were applied at $30 \mathrm{~V}$ (for E13.5) or $33 \mathrm{~V}$ (for E14.5) using $5 \mathrm{~mm}$ electrodes and a square-wave electroporator (50-ms duration; ECM 830; BTX). The uterine horns were then placed back into the abdominal cavity, and the abdomen wall and skin were sutured using surgical needles and thread. The whole procedure was completed within $60 \mathrm{~min}$. E15.5 and E17.5 embryos or P2 animals were processed for tissue analyses. At least three independent experiments were performed, and at least six brains were analyzed for each condition.

Neuronal culture and neurotrophin treatment. Cultured hippocampal neurons were prepared as described previously (Fu et al., 2007). Dissociated hippocampal neurons at 0 DIV were then transfected with shRNA or expression constructs by electroporation using Amaxa Nucleofector system. The expression constructs encoding wild-type Axin and its mutants were first expressed in HEK 293T cells to ensure a comparable expression level. Neurons were plated onto poly-D-lysine-coated coverslips $(0.1 \mathrm{mg} / \mathrm{ml})$ and then incubated at $37^{\circ} \mathrm{C}$ with $5 \% \mathrm{CO}_{2}$. Neuronal morphology was analyzed at 3-5 DIV after plating. For examining the possible roles of Axin in axon extension or degeneration, hippocampal neurons at 3 DIV were transfected with different constructs plus GFPexpressing construct using calcium phosphate precipitation and then fixed at 6 DIV.

Before neurotrophin treatment, cultured neurons at 4 DIV were starved in Neurobasal medium without supplements at $37^{\circ} \mathrm{C}$ for $1 \mathrm{~h}$ and then treated with neurotrophins [brain-derived neurotrophic factor (BDNF) and neurotrophin-3 (NT-3); $50 \mathrm{ng} / \mathrm{ml}$. The neurons were then washed with PBS and lysed in appropriate lysis buffer for Western blotting or coimmunoprecipitation analysis.

Immunohistochemistry. Neurons were fixed with $4 \%$ paraformaldehyde in PBS at $37^{\circ} \mathrm{C}$ for $20 \mathrm{~min}$. After permeabilization and blocking in $0.4 \%$ Triton $\mathrm{X}-100$ containing $1 \mathrm{mg} / \mathrm{ml} \mathrm{BSA}$ at $4^{\circ} \mathrm{C}$ for $30 \mathrm{~min}$, neurons were immunostained with specific primary antibodies at $4^{\circ} \mathrm{C}$ overnight and subsequently with Alexa Fluor-conjugated secondary antibodies at room temperature for $1 \mathrm{~h}$. Coverslips were mounted in Antifade (Invitrogen) and examined using a confocal laser microscopy system (Olympus).

Embryos or animals were killed by cardiac perfusion with 4\% paraformaldehyde. After perfusion, the brains were quickly removed and postfixed in $4 \%$ paraformaldehyde for another $2-3 \mathrm{~h}$ and then cryoprotected in $20 \%$ sucrose for $5-6 \mathrm{~h}$, followed by $30 \%$ sucrose at $4^{\circ} \mathrm{C}$ overnight. The brains were then embedded in O.C.T. medium and cut at $-20^{\circ} \mathrm{C}$ using a cryostat (HM 560; Microm). Perfused brains were cut coronally in 16- to $20-\mu \mathrm{m}$-thick serial sections. After permeabilization and blocking in TBS buffer containing $0.1 \%$ Triton X-100 and 3\% BSA at room temperature 


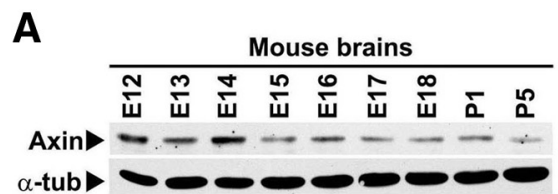

B
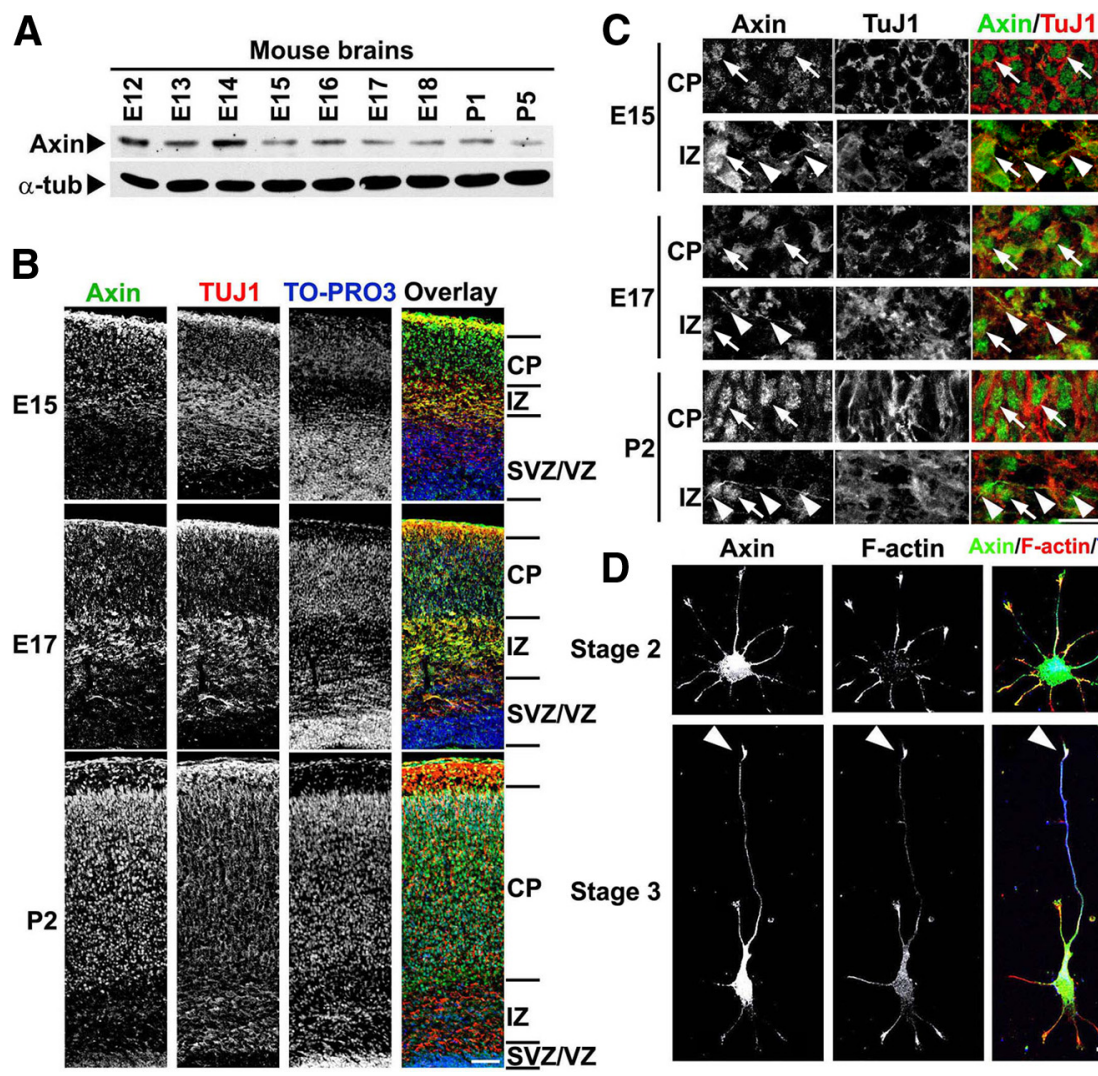

$\mathrm{P}$
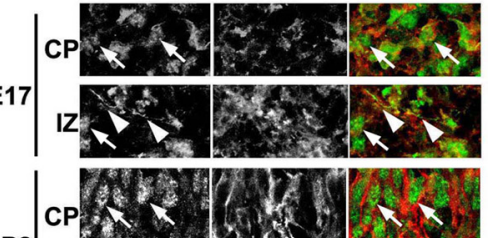

P
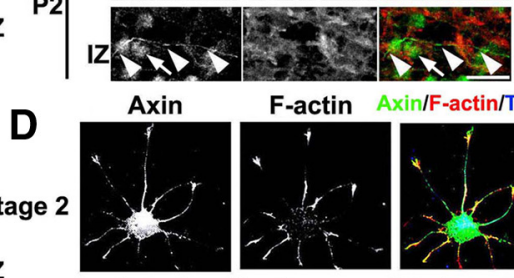

F-actin Axin/F-actin/Tau-1

Figure 1. Axin expression is developmentally regulated during axon formation. $A$, Axin is expressed in the mouse brain during embryonic and early postnatal development. $\alpha$-Tubulin ( $\alpha$-tub) served as a loading control. E, Embryonic day; P, postnatal day. $\boldsymbol{B}$, Expression of Axin protein during development of cortical plate (E15-P2). Typical layers of the cerebral cortex were shown. Mouse brain sections were stained with anti-Axin (green), TuJ1 (red) antibodies and T0-PRO3 iodide (nuclei; blue). SVZ, Subventricular zone; VZ, ventricular zone. Scale bar, $100 \mu \mathrm{m}$. C, Axin protein is detected in the soma and axons of neurons. Axin protein was in the nucleus (arrows) and cytoplasm of neurons, which was marked by TuJ1. Low level of Axin was also detected in the axons (arrowheads). Scale bars, $20 \mu \mathrm{m}$. D, Axin is preferentially enriched at the tips of nascent axons. Cultured hippocampal neurons at stage 2 or at stage 3 were stained with anti-Axin (green), anti-Tau-1 (axon; blue) antibodies together with rhodamine-phalloidin (for F-actin; red). F-actin was concentrated at the peripheral area of growth cones, labeling the tips of neurites or axons. Arrowheads depicted the axon tips. Scale bar, $20 \mu \mathrm{m}$.

for $30 \mathrm{~min}$, brain sections were incubated with specific primary antibodies at $4^{\circ} \mathrm{C}$ overnight and then with corresponding Alexa Fluorconjugated secondary antibodies at room temperature for $1 \mathrm{~h}$. The sections were mounted in Mowiol mounting medium. Nuclei were stained with TO-PRO-3.

Image acquisition and analysis. Confocal images for neuronal morphology of cultured neurons were acquired using Olympus Fluoview FV1000 confocal microscope. $Z$-series images of electroporated mouse brain sections were collected using confocal microscope with a $10 \times$ or $20 \times$ objective using $z$-serial scanning mode ( $1 \mu \mathrm{m}$ step with five to six optical sections). Images of individual neurons were captured with $60 \times$ objective. Images from the same experiment were obtained using identical acquisition settings.

Neuronal polarity was assessed by determining the percentage of no-axon (NA), single-axon (SA), and multiple-axon (MA) neurons. The axon was defined as Tau-1 positive, smi-312 positive, or synapsin I positive, with length $\geq 100 \mu \mathrm{m}$, and at least twice as long as the other shorter processes. For each condition, $\sim 6-10$ coverslips were examined, and at least three independent experiments were performed. The distribution of Axin and GSK-3 $\beta$ were compared at the axonal tips or neurite tips that contain noncollapsed growth cones. The localization of GSK- $3 \beta$ at the neurite tips was quantified by measuring the intensity of GSK- $3 \beta$ immunofluorescence at the neurite tips, normalized by that of the cytosolic marker CMRA.

Neurite length, number of neurites per neuron, and densitometric quantification of protein band intensity were analyzed using NIH ImageJ software.
Statistical analysis. Statistical comparisons to examine whether at least one dataset is different from the rest were performed using Student's $t$ test or nonparametric ANOVA (Friedman's test). Differences between two individual datasets were examined using $t$ test or Kolmogorov-Smirnov test, depending on whether the data are normally distributed. Error bars in the graphs represent SEM. All experiments were performed at least three times except those specifically indicated.

\section{Results}

\section{Axin is required for axon formation in vivo}

To investigate whether Axin is involved in neuronal development, we first studied the expression profile of Axin in the mouse developing cortex (Fig. 1A-C). Axin protein was expressed in mouse brains during early development (E12 to P5; Fig. 1A). The protein was highly concentrated in the $\mathrm{CP}$ and the upper intermediate zone (IZ; Fig. $1 B, C)$, in which neurons reside. The colabeling with neuronal-specific marker $\beta$-tubulin III (TuJ1) suggested that Axin is expressed in cortical neurons, particularly in the nuclei (arrows) and axons (Fig. 1C, arrowheads). We then further examined the subcellular distribution of Axin in cultured hippocampal pyramidal neurons, which is a well-established in vitro model for studying neuronal polarization and axon formation (Dotti et al., 1988; Kaech and Banker, 2006) (Fig. $1 D$ ). Axin protein was expressed in the nuclei and accumulated at the nascent axons of neurons, particularly at their tips (Fig. $1 D$, arrowheads). Collectively, the preferential enrichment of Axin at the growing axonal tips suggests a role of Axin in axon development.

We then studied the role of Axin in axon development by suppressing its expression in the progenitor cells of ventricular zone and their neuronal progeny in the cortex of embryonic mouse using in utero electroporation. Overexpression of shRNA construct that specifically targets Axin (shAxin) in neurons led to a marked reduction of Axin protein (Fig. $2 A-C$ ). After electroporation, the GFP-positive neurons that express either PSUPER (Control) or shAxin were able to reach their final positions at the upper layers of the CP (Fig. 2D-F), indicating that neuronal differentiation or migration was not affected. The control neurons in the upper IZ and the CP at E15.5 then extended fine and long trailing processes (Fig. $2 D$, green arrows), which became axons and projected through the CP and bundled eventually as the commissural axonal tract in the lower IZ (Fig. 2D). However, silencing of Axin expression led to impaired axon initiation (Fig. $2 D$ ) and resulted in the absence of the GFP-positive axonal tract (Fig. 2D). The number of GFP-positive Axin knocked down neurons in IZ/CP that extended trailing processes/axons was significantly reduced (Fig. 2D,G), whereas the leading processes of these neurons did not show observable abnormality (Fig. 2D). Furthermore, severely impaired axon formation was observed in Axin knocked down neurons at later developmental stages (i.e., E17.5 and P2), confirming that Axin depletion causes an inhibi- 

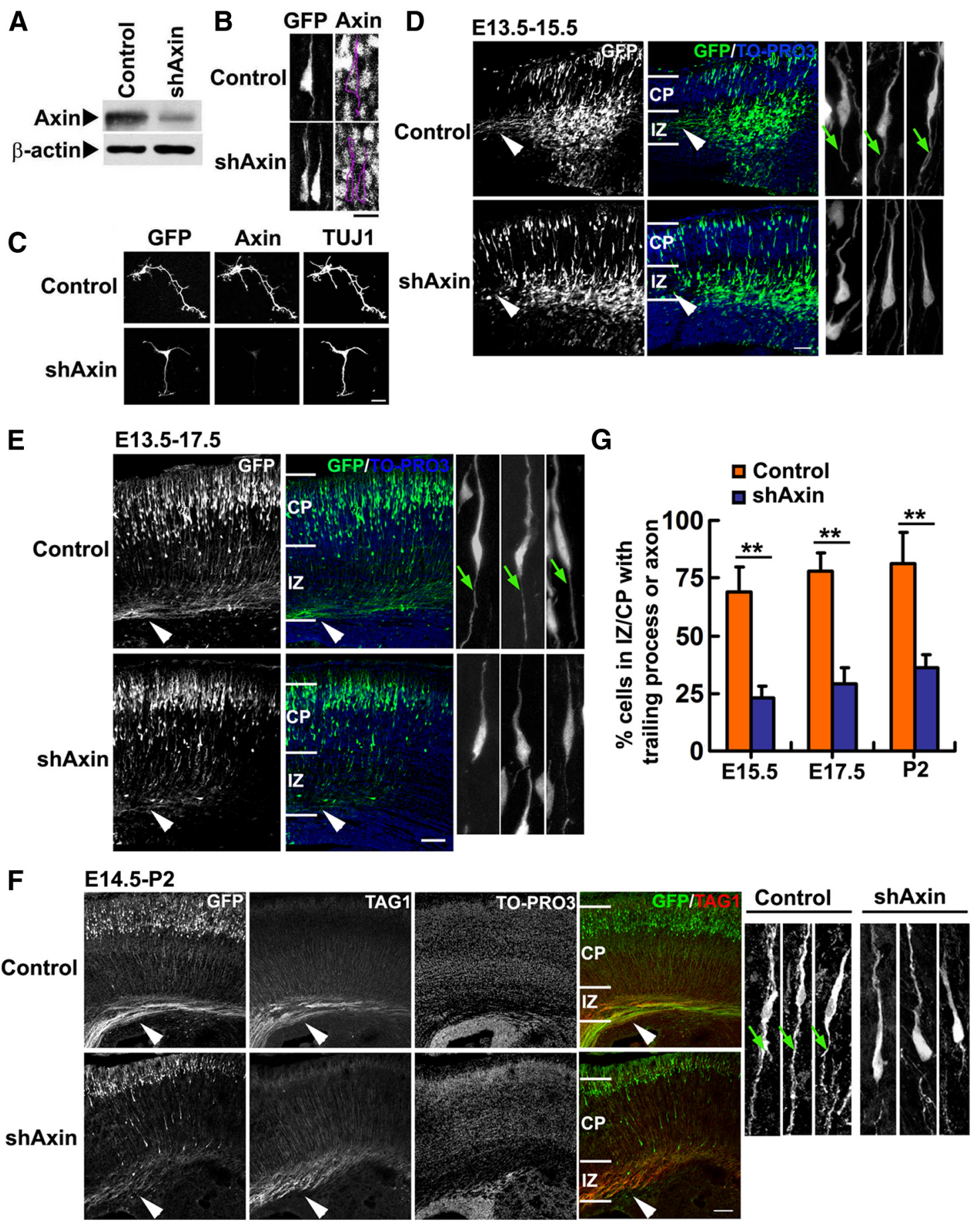

Figure 2. Axin is required for axon formation during mouse neocortical development. $A-C$, Endogenous Axin expression in neurons was silenced by pSUPER-Axin shRNA (shAxin) construct. $A$, Cultured hippocampal neurons at 0 DIV were transfected with shAxin construct. Protein lysates were collected at 3 DIV after transfection and subjected to Western blot analysis for Axin. $\boldsymbol{B}$, Mouse brains were in utero electroporated with shAxin construct and GFP expression construct at embryonic day 14.5. Brain sections were collected $2 \mathrm{~d}$ later and were stained with Axin antibody. Transfected cells were outlined in purple. C, Cultured hippocampal neurons at 0 DIV were transfected with shAxin construct. Immunostaining was performed at 3 DIV. Scale bar, $20 \mu \mathrm{m}$. D-F, Knockdown of Axin inhibits axon formation in developing mouse brains. Expression of Axin protein in cerebral cortical neurons was suppressed using in utero electroporation. shAxin construct was coelectroporated with GFP expression construct into mouse brains at E13.5 or E14.5. After allowing in vivo development, brain sections were obtained from mouse pups at E15.5 (D), E17.5 (E), or P2 $(\boldsymbol{F})$. For each condition, at least three independent experiments were performed and at least six brains were examined. TAG1, Axonal maker. T0-PR03 iodide stained the nuclei. Arrowheads indicated the axonal tracts. Green arrows indicated the trailing processes/axons of control neurons. Scale bar, $50 \mu \mathrm{m}$. G, Quantification of the percentage of neurons ( $~ 80$ individual neurons for each condition) with trailing processes/axons. ${ }^{* *} p<0.01, n=3$, Student's $t$ test, mean \pm SEM.

tion of axon formation rather than a delay in axonal outgrowth (Fig. $2 E-G$ ). Furthermore, although Axin knocked down neurons failed to initiate axons, the neighboring non-electroporated neurons were able to extend axons and form axonal tracts [shown by the positive staining for TAG1, a commissural axonal marker (Fujimori et al., 2000); Fig. 2 F], suggesting that Axin depletion inhibits axon formation autonomously in the cerebral cortex. 
A

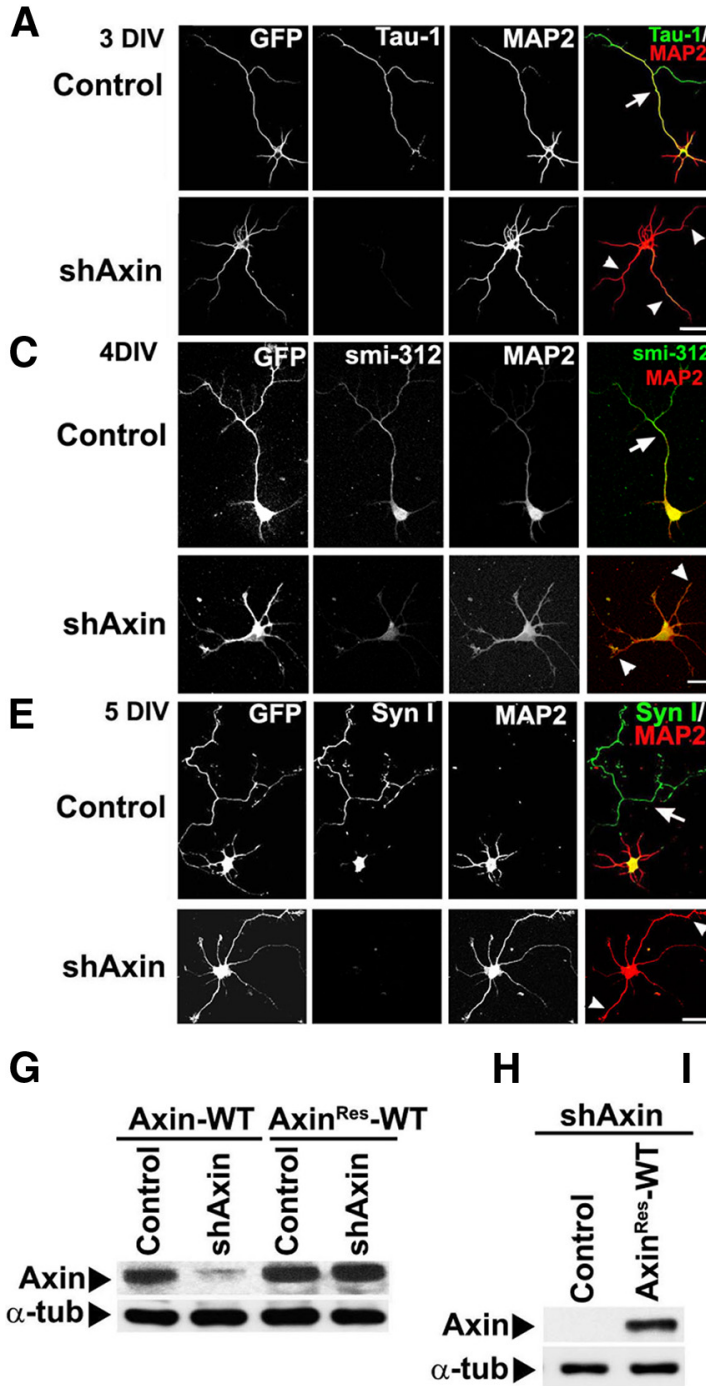

B

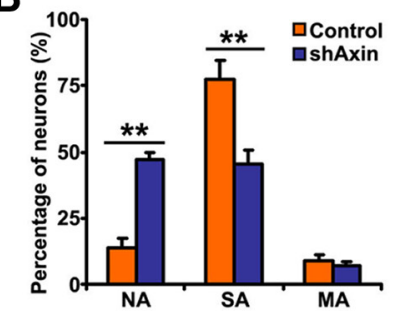

D

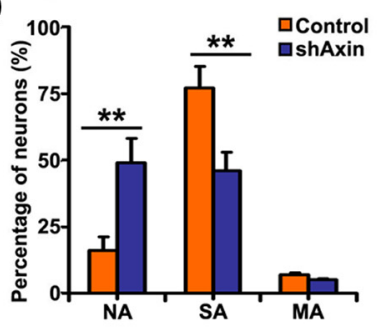

F
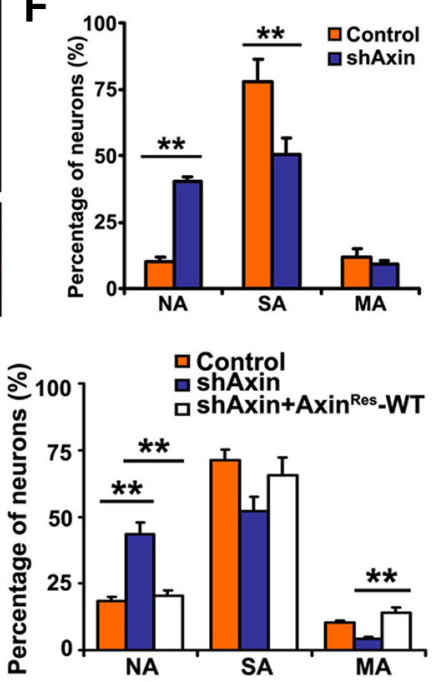

$\mathbf{J}$

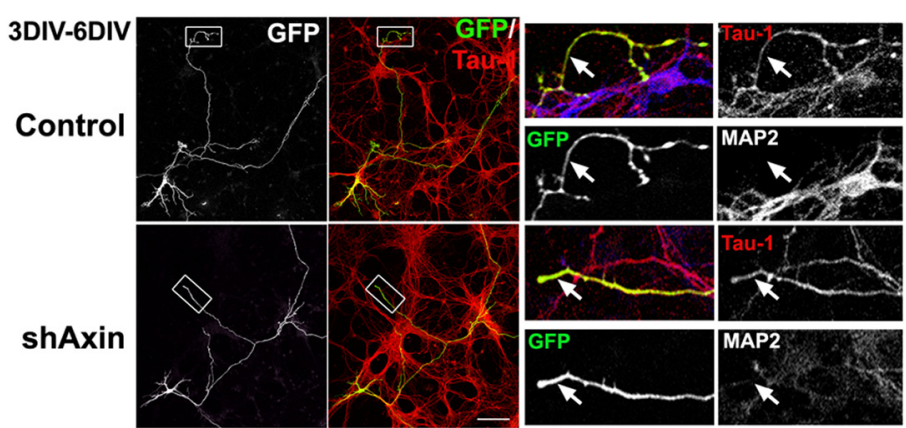

Figure 3. Axin directs axon formation in cultured hippocampal neurons. $A-F$, Axin is required for axon formation. Dissociated hippocampal neurons were transfected with shAxin construct, together with GFP expression construct, and fixed at 3 DIV $(\boldsymbol{A}, \boldsymbol{B}), 4$ DIV $(\boldsymbol{C}, \boldsymbol{D})$, or 5 DIV $(\boldsymbol{E}, \boldsymbol{F})$ after transfection. Neurons were costained with antibodies against GFP, axonal markers Tau- 1 (green), smi-312 (green), or synapsin I (Syn l; green), and dendritic marker MAP2 (red) as indicated. The axon was defined as Tau-1, smi-312, or synapsin I positive, longer than $100 \mu \mathrm{m}$, and at least twice as long as the other processes. Arrows indicated the axons; arrowheads indicated the non-axon neurites. Scale bar, $20 \mu \mathrm{m} . \boldsymbol{B}, \boldsymbol{D}, \boldsymbol{F}$, Quantitative analyses of axonal phenotypes. The axonal phenotypes of transfected hippocampal neurons were classified into three groups: NA (no-axon; negative for Tau-1, smi-312, or Syn I but positive for MAP2), SA (single-axon), and MA (multiple-axon) neurons. More than 300 neurons were examined and quantified for each condition. Data were presented as mean \pm SEM; ${ }^{* *} p<0.01, n=3$, shAxin versus control (Student's $t$ test). G-I, Expression of shRNA-resistant Axin restores axon formation in Axin-deficient neurons. G, Expression of shRNA-resistant Axin (Axin ${ }^{\text {Res}-W T) ~ i n ~ H E K ~ 293 T ~ c e l l s . ~ H E K ~ 293 T ~ c e l l s ~ w e r e ~ t r a n s f e c t e d ~ w i t h ~ e x p r e s s i o n ~ c o n s t r u c t s ~ e n c o d i n g ~ w i l d-t y p e ~(A x i n-W T) ~ o r ~}$ shRNA-resistant Axin (Axin ${ }^{\text {Res }}$-WT) together with shAxin construct as indicated. $\boldsymbol{H}$, shRNA-resistant Axin construct restores the expression of Axin protein in shAxin-transfected hippocampal neurons. $I$, Expression of shRNA-resistant Axin rescues axon formation in Axin-deficient neurons. More than 300 neurons were examined and quantified for each condition. Data were presented as mean $\pm \mathrm{SEM}^{*} *{ }^{*} p<0.01, n=3$, one-way ANOVA. J, Knockdown of Axin does not cause axon degeneration or a transition of

Axin is important for axon initiation in cultured neurons

We then examined whether and how Axin regulates axon formation autonomously in cultured neurons. Cultured hippocampal neurons were cotransfected with shAxin and GFP constructs and then cultured for 3-5 d. Morphology of the transfected neurons (labeled with GFP) was visualized by costaining with axon-specific markers Tau-1 (Mandell and Banker, 1996), smi-312 (Ulfig et al., 1998), or synapsin I (Fletcher et al., 1991), together with a dendritic marker MAP2 (Cáceres et al., 1986; Dotti et al., 1988). Neurons were classified into three groups based on the number of axons they possess: NA, SA, and MA neurons. Consistent with the in vivo effect of Axin, silencing of Axin expression inhibited axon initiation in cultured neurons (Fig. $3 A, B$ ). Similar observation was obtained when Axin expression was suppressed for prolonged period, further suggesting that depletion of Axin inhibits axon initiation but does not delay axon specification (Fig. 3C-F). To confirm that the absence of axon is specific to Axin knockdown, we showed that re-expression of shRNA-resistant Axin (Axin ${ }^{\text {Res-WT) in }}$ Axin-depleted neurons restored axon outgrowth (Fig. 3G-I).

Furthermore, knockdown of Axin did not trigger axonal degeneration or switching of axon into dendrite, suggesting that Axin specifically regulates axon initiation. Cultured hippocampal neurons (3 DIV), at the stage when axons are established, were cotransfected with shAxin and GFP constructs. Similar to that observed in control neurons, Axin-depleted neurons had a single axon (arrows; $93 \pm 3 \%$ ), which was positive for Tau-1 and negative for MAP2 immunostaining (Fig. 3J). In addition, the total neurite length and average neurite number were not markedly altered in these Axin knocked down neurons (data not shown). Collectively, our data suggest that Axin is selectively important for axon initiation but not for maintaining the axonal identity or neurite extension.

Axin regulates the activity and localization of GSK-3 $\beta$ during axon initiation

Given that Axin is enriched in the neuronal nuclei and along the axons (Fig. 1), we

axon to dendrite. Cultured neurons were cotransfected with shAxin construct and GFP expressing construct at 3 DIV. The neurons were then fixed at $3 \mathrm{~d}$ after transfection and stained with antibodies for Tau- 1 and MAP2. Arrows indicated the magnified axonal distant ends, which is positive for Tau-1 (red) but negative for MAP2 (blue). Scale bar, $50 \mu \mathrm{m}$. 
studied whether cytosolic or nuclear Axin contributes to axon initiation. Axin possesses the nuclear localization signal (NLS; amino acids 350-360 and 413-423) and nuclear export signal (NES; amino acids 414-424), the mutation of which abolishes the nuclear localization or nuclear export of Axin, respectively (Cong and Varmus, 2004; Wiechens et al., 2004). Interestingly, overexpression of Axin or its nuclear localization mutant Axin ${ }^{\text {Res }}$ NLSm, but not the nuclear export mutant

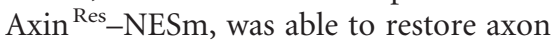
formation in Axin-depleted neurons (Fig. $4 A, B)$, suggesting that the cytosolic pool of Axin is important for axon formation.

Cytosolic Axin is a scaffold protein of the canonical Wnt signaling, in which Axin interacts with $\beta$-catenin and facilitates its phosphorylation and degradation (Ikeda et al., 1998). We then investigated whether Axin regulates axon formation through the canonical Wnt signaling by interacting with and destabilizing $\beta$-catenin. Overexpression of Axin mutant that lacks the $\beta$-catenin-binding domain (Axin $\Delta \beta$-cat) did not inhibit axon formation, but in contrast, the mutant functioned similarly as the wild-type Axin (Fig. 4C). Thus, Axin regulates axon formation in a manner independent of the canonical Wnt signaling.

Axon formation is regulated by the local stabilization of microtubules in one of the neuronal processes (Witte et al., 2008). Precise inhibition of GSK-3 $\beta$ (marked by its phosphorylation at Ser9) is necessary and sufficient for promoting axon formation, extension, and branching through controlling the microtubule stability via various microtubule regulators, such as CRMP-2, Tau, and MAP1B (Zhou et al., 2004; Jiang et al., 2005; Kim et al., 2006; Yoshimura et al., 2006). Interestingly, Axin facilitates the inhibitory phosphorylation of GSK- $3 \beta$ in PC12 neuronal cells (Fukumoto et al., 2001). Thus, we examined whether Axin mediates axon initiation through stabilization of the microtubules in a GSK-3 $\beta$-dependent manner. We found that Axin interacted with GSK-3 $\beta$ in cultured neurons at 2.5 DIV, the stage of axon initiation (Fig. $4 D$ ). Furthermore, knockdown of Axin reduced the pSer9 level of GSK-3 $\beta$ in neurons (Fig. 4E), accompanied by an increased phosphorylation of CRMP-2 at Thr514 (Fig. 4E). Phosphorylation of CRMP-2 at Thr514 has been shown to reduce its interaction with tubulin heterodimers, leading to a decreased assembly of microtubule and increased instability of the microtubule network (Fukata et al., 2002), thereby resulting in inhibition of axon formation (Inagaki et al., 2001). Consistent with this notion, the levels of Ace- $\alpha$-tub and de-
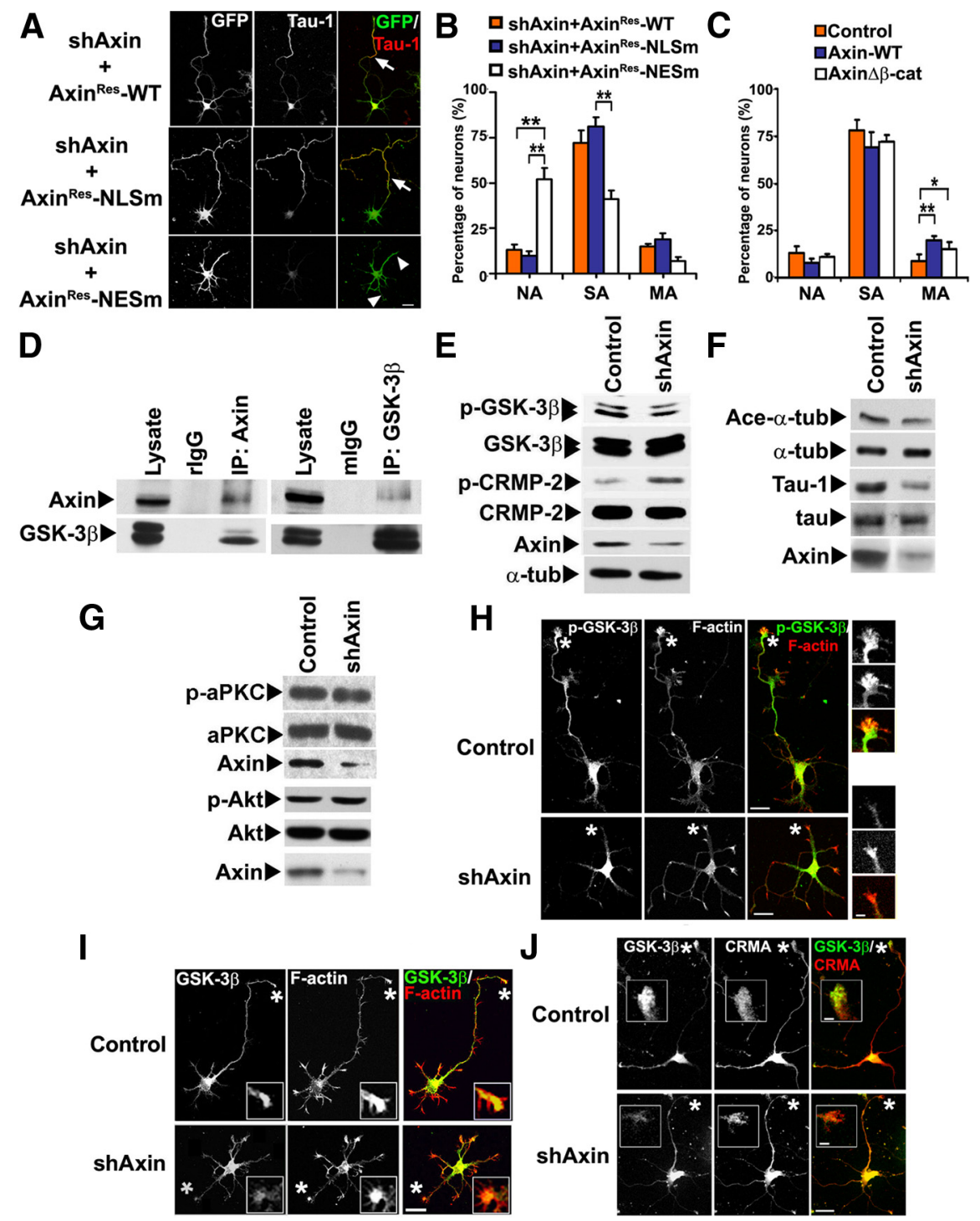

Figure 4. Cytosolic Axin regulates the microtubule stability through inhibitory phosphorylation of GSK-3 $\beta$. A, B, Axon formation is attributable to the cytosolic pool of Axin in cultured hippocampal neurons. Expression of the shRNA-resistant wild-type Axin (Axin ${ }^{\text {Res }}$-WT) or its mutant Axin ${ }^{\text {Res }}$-NLSm, but not the Axin ${ }^{\text {RES }}$-NESm, restored the axon formation in Axin-deficient neurons. Scale bar, $20 \mu \mathrm{m}$. More than 200 neurons were examined and quantified for each condition. Data were presented as mean \pm SEM; ${ }^{* *} p<0.01, n=3$. C, Axin-directed axon formation is independent of the canonical Wnt signaling. Cultured hippocampal neurons were transfected with vector (Control), Axin-WT, or Axin $\Delta \beta$-cat (Axin mutant lacking the binding domain for $\beta$-catenin) as indicated. More than 300 neurons were analyzed and quantified for each condition. ${ }^{*} p<0.05,{ }^{* *} p<0.01, n=3$, Student's $t$ test, mean \pm SEM. $\boldsymbol{D}$, Axin interacts with GSK-3 $\beta$ during axon formation in cultured cortical neurons at 2.5 DIV. Rabbit or mouse lgG (rlgG or mlgG) was used as negative control. $E$, Knockdown of Axin increases activity of GSK-3 $\beta$. Silencing Axin expression in cultured hippocampal neurons led to a reduction of the phospho-GSK-3 $\beta$ at Ser9 (p-GSK-3 $\beta ; \sim 40 \%$ reduction, $p<0.05$ ) and an increase of phospho-CRMP- 2 at Thr514 ( $p$-CRMP-2; $\sim 2.4$-fold increase, $p<0.05$ ), which resulted in impaired microtubule stability. $F$, Knockdown of Axin reduces the level of Ace- $\alpha$-tub and dephosphorylated tau (Tau-1) in cultured neurons, indicating the impaired microtubule stability. G, Loss of Axin does not affect aPKC and Akt activity in cultured neurons. p-aPKC, phospho-aPKC (at Thr410/403); p-Akt, phospho-Akt (at Ser473). $\boldsymbol{H}$, Knockdown of Axin abolishes accumulation of phospho-GSK-3 $\beta$ (Ser9) at the tip of the axon or the longest neurite. Neurons cotransfected with shAxin and GFP constructs were fixed and costained with antiphospho-GSK-3 $\beta$ antibody (green) and rhodamine-phalloidin to indicate the growth cones (F-actin; red). Magnified views of the longest neurite tips (asterisks) were shown. Scale bar, $20 \mu \mathrm{m}$. I, J, Knockdown of Axin leads to the mislocalization of GSK-3 $\beta$ from the tip of the axon or the longest neurite. Magnified views of the longest neurite tips (asterisks) were shown (insets). CMRA is a cytosolic marker, labeling the neuronal soma and processes. Scale bar, $20 \mu \mathrm{m}$.

phosphorylated tau (Tau-1), which are markers of microtubule stability in neurons (Mandelkow et al., 1995), were found to be reduced in Axin knocked down neurons (Fig. 4F).

Although the phosphorylation of GSK-3 $\beta$ at Ser9 during axon formation is regulated by two upstream kinases, aPKC or Akt 
A
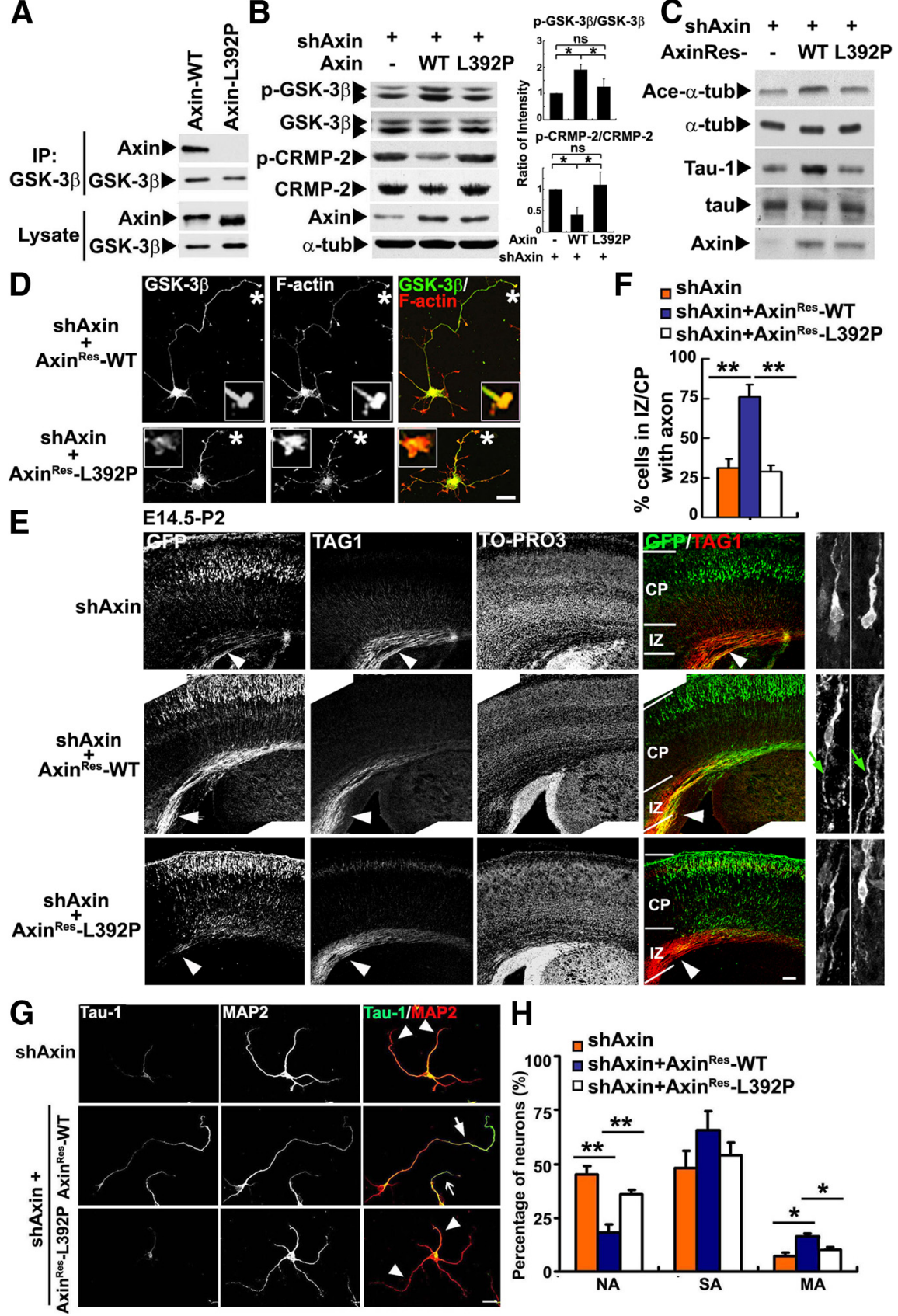

Figure 5. The specific interaction between Axin and GSK-3 $\beta$ is required for GSK-3 $\beta$ activity regulation and axon formation. $\boldsymbol{A}$, Mutation of Axin at Leu392 site to proline abolishes the interaction of Axin and GSK-3 $\beta$. HEK 293T cells were transfected with Axin-WT or Axin-L392P. Protein lysate was coimmunoprecipitated with GSK-3 $\beta$ antibody. Western blot analysis for Axin was performed. $\boldsymbol{B}$, The Axin-GSK-3 $\beta$ interaction is essential for inhibiting GSK-3 $\beta$ activity in cultured neurons. ${ }^{*} p<0.05$; ns, not significant; $n=3$, Student's $t$ test, mean \pm SEM. $\boldsymbol{C}$, Axin-GSK-3 $\beta$ interaction in neurons is important for maintaining the level of Ace- $\alpha$-tub and dephosphorylated tau (Tau-1). D, Axin-GSK-3 $\beta$ interaction is required for the proper localization of GSK-3 $\beta$. Scale bar, $20 \mu \mathrm{m}$. $\boldsymbol{E}$, The specific Axin-GSK-3 $\beta$ interaction is required for axon formation during mouse brain development. Note that a small proportion of neurons expressing Axin-L392P were found in the IZ or the lower CP, indicating that the migration of these neurons was slightly affected. TAG1, Axonal maker. Arrowheads indicated the axonal tracts, whereas green arrows depicted the trailing processes/axons. Scale bar, $50 \mu \mathrm{m}$. $\boldsymbol{F}$, Quantification of the percentage of neurons ( $\sim 60$ individual neurons for each condition) with trailing processes/axons. ${ }^{* *} p<0.01, n=3$, Student's $t$ test, mean \pm SEM. $\mathbf{G}, \boldsymbol{H}$, Axin-GSK-3 $\beta$ interaction is essential for axon formation in cultured hippocampal neurons. Although expression of shRNA-resistant Axin restored axon formation in Axindeficient neurons, Axin-L392P expression failed to rescue axon formation. Big arrow indicated the axon; small arrow indicated the neighboring untransfected axon; arrowheads indicated non-axonal neurites. More than 300 neurons were analyzed and quantified for each condition. ${ }^{*} p<0.05 ;{ }^{* *} p<0.01, n=3$, one-way ANOVA, mean \pm SEM. Scale bar, $20 \mu \mathrm{m}$.
(Etienne-Manneville and Hall, 2003; Jiang et al., 2005), Axin depletion did not regulate the activity of these kinases (Fig. $4 G)$. Moreover, silencing of Axin expression reduced phospho-GSK-3 $\beta$ at Ser9 along the axon, especially disrupting its accumulation at the axonal tip (Fig. $4 H$ ), and caused a significant reduction of GSK-3 $\beta$ level at the tips of the axons or of the longest neurites (control, $2.4 \pm 0.3$ when compared with shAxin, $0.6 \pm 0.1$, $p<0.01$; Fig. $4 I, J)$, indicating that Axin is important for the proper localization of GSK-3 $\beta$ in neurons. Thus, it is interesting to speculate that the mislocalization of GSK-3 $\beta$ in Axin knocked down neurons renders GSK-3 $\beta$ unable to be phosphorylated by its upstream kinases aPKC or Akt, which are preferentially enriched at the axonal tips (Zhou et al., 2004). Together, our findings suggest that Axin regulates the localization of GSK- $3 \beta$ and hence its activity, thereby modulating microtubule stability.

\section{Interaction of Axin and GSK-3 $\beta$ is}

critical for the inactivation of

GSK-3 $\beta$ and axon formation

A single mutation of Axin at Leu392 to proline abolished the association of Axin with GSK-3 $\beta$ (Fig. 5A) (Smalley et al., 1999). Moreover, re-expression of this point mutant of Axin in Axin -knocked down neurons failed to restore the inhibitory phosphorylation and the polarized distribution of GSK-3 $\beta$ (Fig. $5 B, D$ ), as well as the precise phosphorylation of microtubule regulators, including CRMP-2, tau, and acetylated $\alpha$-tubulin (Fig. $5 B, C$ ). Importantly, we found that the interaction of Axin and GSK- $3 \beta$ is critically required for axon formation in the cortex. Unlike the wild-type Axin (Axin ${ }^{\text {Res }}-\mathrm{WT}$ ), expression of the Axin ${ }^{\text {Res }}$-L392P mutant in Axin knocked down neurons was unable to rescue axon formation in the developing cerebral cortex (Fig. 5E,F) or in cultured hippocampal neurons (Fig. $5 G, H)$. Together, these findings suggest that the specific interaction of Axin and GSK-3 $\beta$ ensures the precise regulation of both localization and activity of GSK$3 \beta$, which is critical for controlling the phosphorylation status of microtubule regulators and thereby enhances axon formation.

\section{Cdk5 phosphorylates Axin in vivo}

A plethora of microtubule regulators have been demonstrated as the substrates of Cdk5. Through phosphorylation of these proteins, Cdk5 was suggested to be essential for the assembly or stabilization of mi- 
crotubule network (Smith, 2003). Thus, it is interesting to examine whether the action of Axin on the microtubule organization during axon formation is regulated by Cdk5. The presence of four potential Cdk5 phosphorylation sites on Axin (Fig. $6 A$ ), together with the importance of Cdk5 in axon development, prompted us to examine whether Cdk5 phosphorylates and regulates the functions of Axin. Coexpression of the Cdk5 activator p35 with wild-type Axin in HEK293T cells increased the Ser/Thr phosphorylation of Axin (Fig. 6B). Single mutation of Thr485 of Axin to alanine substantially reduced its phosphorylation, suggesting that Thr485 is the major Cdk5 phosphorylation site (Fig. $6 \mathrm{~B}$ ). We then generated the phospho-specific Axin antibody against Thr485 and showed that the active Cdk5/ p25 complex phosphorylates Axin at Thr485 using in vitro phosphorylation assay (Fig. 6C). In contrast, similar phosphorylation was not observed with an Axin mutant with Thr485 site mutated to alanine (Fig. 6C), indicating that Cdk5 phosphorylates Axin at Thr485. Phosphorylation of Axin was substantially reduced after treatment with CIP, further confirming the specificity of the phosphospecific antibody (Fig. 6D).

We then examined whether Cdk5 phosphorylates Axin at Thr485 in vivo. Inhibition of Cdk5 activity in cultured neurons at 2 and 5 DIV using the selective inhibitor Ros reduced p-Thr485 Axin level (Fig. 6E), indicating that Axin is phosphorylated by Cdk5 during axon initiation and extension. Importantly, p-Thr485 Axin was barely detected in $C d k 5^{-/-}$cortical neurons (Fig. $6 F$ ), as well as in p35 knockdown or $p 35^{-/-}$cortical neurons (Fig. 6G). Moreover, Cdk5dependent phosphorylation was detected in both the cytosol and nuclei of cultured neurons during the stage of axon initiation (Fig. $6 H$ ). Together, these results demonstrate that Cdk5 phosphorylates Axin at Thr485 in neurons during axon formation.

\section{Cdk5-dependent phosphorylation of Axin is important for axon formation}

We next investigated the importance of Cdk5-dependent Axin phosphorylation in axon formation. Inhibition of Cdk5-mediated phosphorylation of Axin by Ros abolished the interaction of Axin with GSK-3 $\beta$ in neurons (Fig. 7A). Moreover, the Axin phosphodeficient mutant (Axin-T485A) bound to GSK-3 $\beta$ less effectively than that of the wild type and the phospho-mimetic mutant (Axin-T485E; Fig. 7B), indicating that the phosphorylation of Axin at Thr485 is critical for controlling the direct interaction of Axin and GSK-3 $\beta$. Because inhibition of Cdk5 may indirectly activate GSK-3 $\beta$ (Morfini et al., 2004), to confirm that the AxinGSK-3 $\beta$ interaction is specifically dependent on the Cdk5mediated phosphorylation of Axin, we showed that activation of GSK-3 $\beta$ by phosphatidylinositol 3-kinase (PI3K) inhibitor Wort cannot disrupt Axin-GSK-3 $\beta$ association nor increase the phospho-Axin (Thr485) level (Fig. 7C). Thus, our data suggest that phosphorylation of Axin at Thr485 or its interaction with

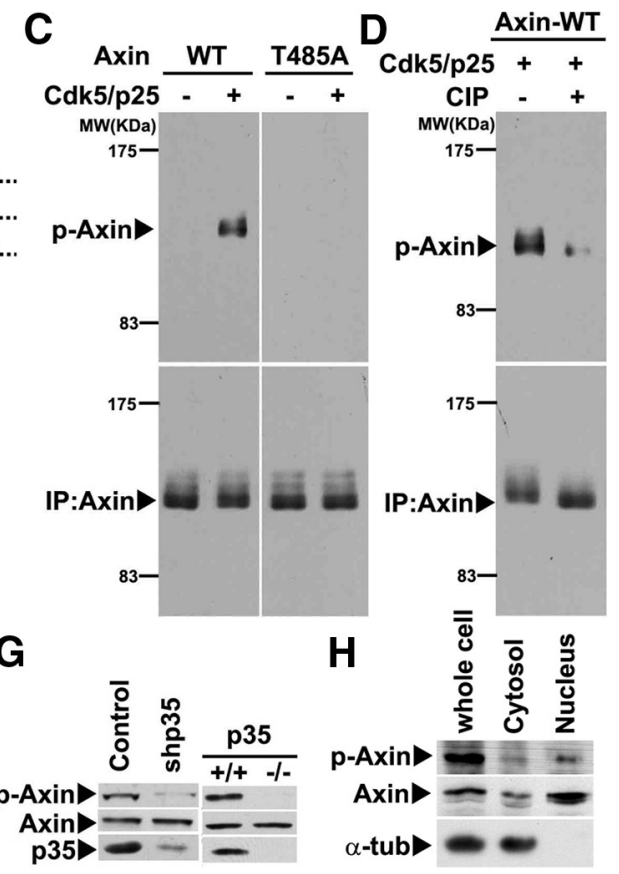

C $d \mathrm{k} 5$ phosphorylates Axin in cultured neurons and in developing mouse brains. $\boldsymbol{A}$, The putative $(\mathrm{dk} 5$ phosphorylation (mouse (m), rat (r), and human (h)]. B, Cdk5 phosphorylates Axin at Thr485 in HEK 293T cells. Axin

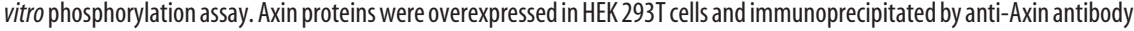
phosphorylation at Thr485 in cultured neurons. $\boldsymbol{H}$, Axin phosphorylation was detected both in the cytosol and nuclei of cultured neurons. $\alpha$-Tubulin was used as the cytosolic protein marker.

GSK-3 $\beta$ in neurons is not regulated by GSK-3 $\beta$ during axon formation. Interestingly, we found that the Cdk5-dependent phosphorylation of Axin is important for the proper localization and inhibitory phosphorylation of GSK-3 $\beta$, as well as reduced phosphorylation of CRMP-2 (Fig. $7 D, E$ ). The phospho-deficient mutant Axin ${ }^{\text {Res }}$-T485A failed to rescue axon formation in Axin knocked down neurons (Fig. $7 F-I$ ). Together, these results indicate that Cdk5-dependent phosphorylation of Axin is crucial for the direct interaction of Axin and GSK-3 $\beta$, which inhibits GSK-3 $\beta$ activity and promotes axon formation during development of the cerebral cortex.

Neurotrophin stimulation enhances Axin phosphorylation, Axin-GSK-3 $\beta$ interaction, and inactivation of GSK-3 $\beta$

Inactivation of GSK-3 $\beta$ is induced by neurotrophins during axon formation (Yoshimura et al., 2005; Kim et al., 2006). Consistent with previous reports, treatment with BDNF or NT-3 robustly enhanced the inhibitory phosphorylation of GSK-3 $\beta$ at Ser9 and resulted in reduced phosphorylation of CRMP-2 in neurons (Fig. 8A). In contrast, knockdown of Axin abolished the neurotrophin-induced phosphorylation of GSK-3 $\beta$ and prevented the decrease of phosphorylated CRMP-2 level (Fig. $8 \mathrm{~A}$ ). Thus, Axin plays an important role in mediating the action of neurotrophins on inhibiting GSK-3 $\beta$ activity. We next examined whether Cdk5-dependent phosphorylation of Axin is involved in the neurotrophin-dependent inactivation of GSK-3 $\beta$. BDNF or NT-3 stimulation increases the level of phospho-Axin at Thr485 in neurons $(\sim 50 \%$; Fig. $8 B)$, concomitant with an enhanced in- 
A

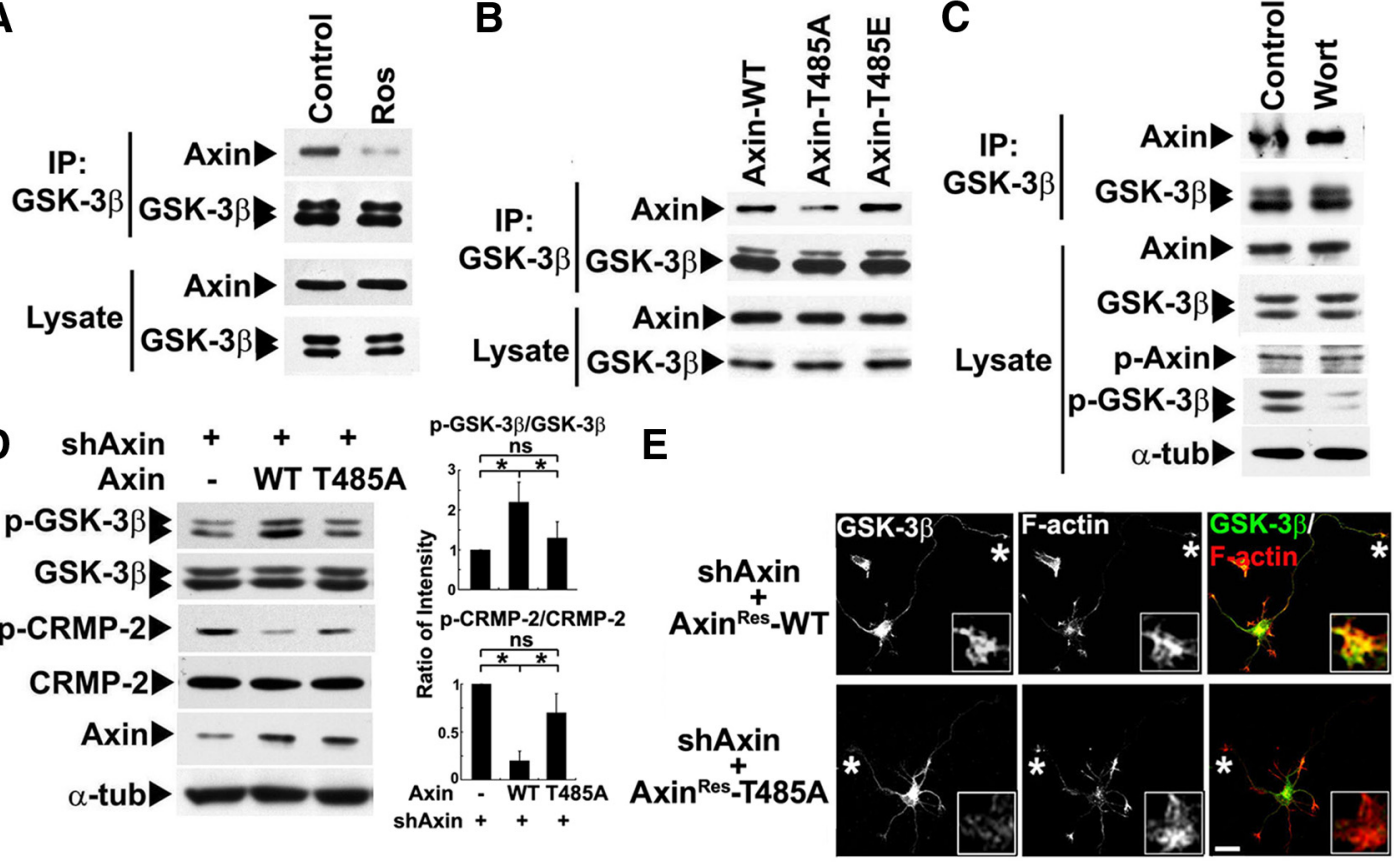

F

\section{E14.5-P2}

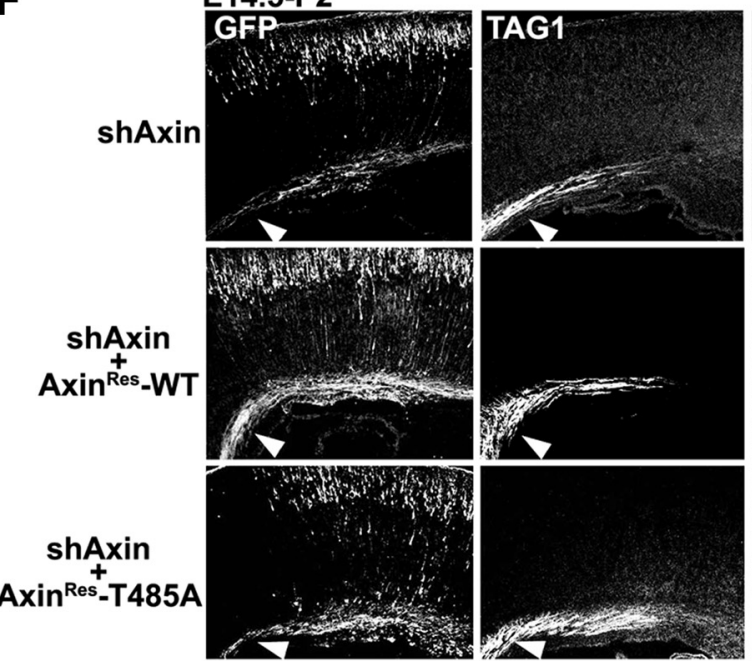

G ushAxin ashAxin+Axin Res-WT 口shAxin+Axin ${ }^{\text {Res-T485A }}$

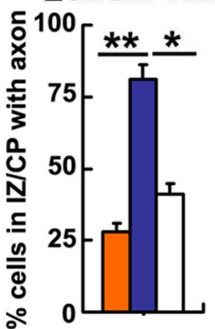

$\mathrm{H}$

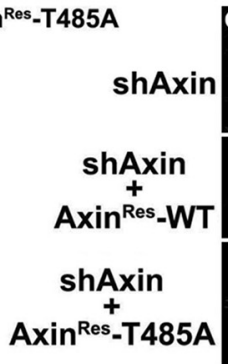

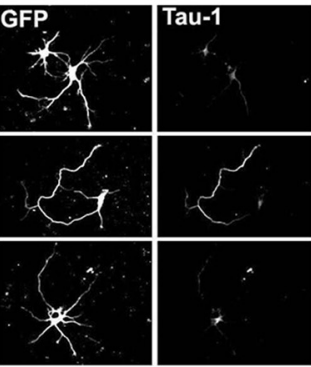

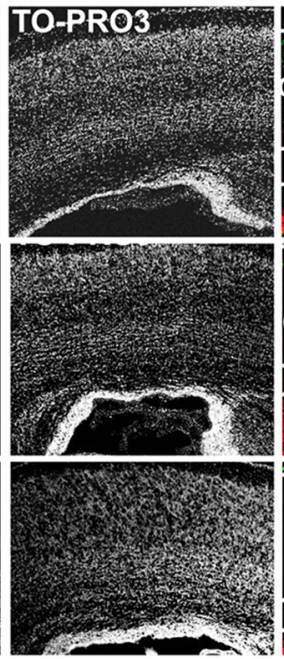

I
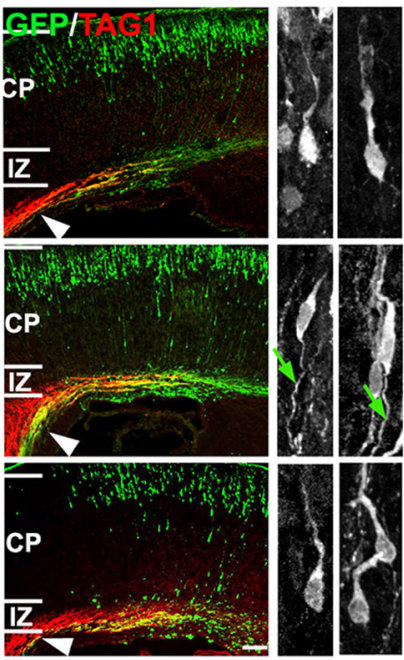

ashAxin $\left.\stackrel{\circ}{0}^{100}\right] \begin{aligned} & \text { ashAxin+Axin Res }-W T \\ & \text { ashAxin+Axin }\end{aligned}$
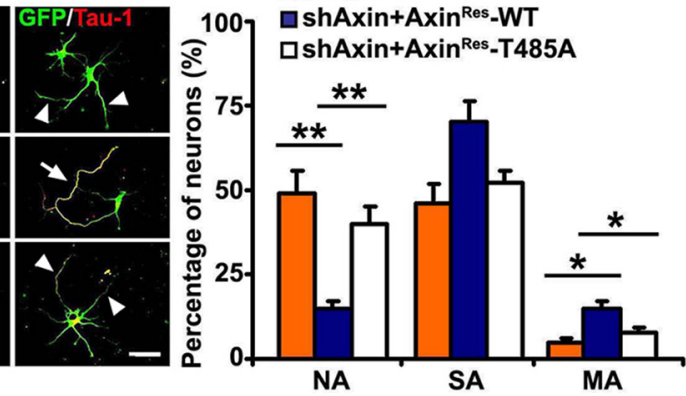

Figure 7. Cdk5-dependent phosphorylation of Axin is required for axon formation through regulating Axin-GSK-3 $\beta$ interaction and thus GSK-3 $\beta$ inhibition. A, Cdk5 activity is required for Axin-GSK-3 $\beta$ interaction. Ros was used to inhibit Cdk5 activity. $B$, Cdk5-dependent phosphorylation of Axin is essential for the interaction of Axin and GSK-3 $\beta$. Wild-type Axin or its phosphorylation point mutants were overexpressed in HEK 293T cells as indicated, and the interaction of Axin with endogenous GSK-3 $\beta$ was examined by coimmunoprecipitation using GSK-3 $\beta$ antibody. C, GSK-3 $\beta$ activation did not affect Axin-GSK-3 $\beta$ interaction. Treating neurons (3 DIV) with Wort, a PI3K inhibitor, upregulated GSK-3 $\beta$ activity, shown by the reduction of phospho-GSK-3 $\beta$ (at Ser9). Wort treatment did not regulate the level of $\mathrm{p}$-Axin, indicating that Axin was not phosphorylated by GSK-3 $\beta$ at Thr 485 in neurons. D, Cdk5-dependent phosphorylation of Axin is required for inhibiting GSK-3 $\beta$ activity. shRNA resistant constructs of Axin WT or its phosphorylation deficient mutant (T485A) was coexpressed together with the shAxin construct in cultured neurons. Western blot analysis for $p$-GSK-3 $\beta$ and $p$-CRMP-2 was performed. ${ }^{*} p<0.05 ; n s$, not significant; $n=3$, Student's $t$ test, mean \pm SEM. $E$, Cdk5-dependent phosphorylation of Axin was required for proper localization of GSK-3 $\beta$ in cultured neurons at 2.5 DIV. Magnified views of the longest neurite tips (asterisks) were shown (insets). Scale bar, $20 \mu \mathrm{m}$. F, Phosphorylation of Axin at Thr 485 was required for axon formation during mouse brain development. TAG1, Axonal maker. Arrowheads indicate the axonal tracts, whereas green arrows indicated the trailing processes/axons. Scale bar, $50 \mu \mathrm{m}$. G, Quantification of the percentage of neurons ( $~ 60$ individual neurons for each condition) with trailing processes/axons. ${ }^{*} p<0.05,{ }^{* *} p<0.01, n=3$, (Figure legend continues.) 
teraction between Axin and GSK-3 $\beta$ (Fig. $8 C)$. Importantly, blocking the Cdk5dependent phosphorylation of Axin by Ros abolished the neurotrophin-induced Axin-GSK- $3 \beta$ interaction in neurons and reduced the inhibitory phosphorylation of GSK-3 $\beta$ (Fig. $8 D$ ). Together, our findings suggest that neurotrophin stimulates Axin phosphorylation, which enhances AxinGSK-3 $\beta$ interaction, resulting in inactivation of GSK-3 $\beta$.

\section{Discussion}

In the present study, we demonstrate that Cdk5-dependent phosphorylation of Axin is critical for axon formation during cerebral cortex development. We show that depletion of Axin in neurons abolish axon initiation both in vitro and in vivo. Importantly, Cdk5 phosphorylates Axin, and this specific phosphorylation mediates the action of Axin in axon establishment through regulation of the GSK-3 $\beta$-dependent microtubule stabilization. Inhibition of Cdk5dependent phosphorylation of Axin causes an aberrant increase in GSK- $3 \beta$ activity through perturbing the interaction of Axin with GSK- $3 \beta$ and results in reduced microtubule stability. We further show that Cdk5dependent phosphorylation of Axin is induced in neurons during stimulation with extracellular cue for axon formation, i.e., BDNF. Thus, our findings provide novel insights into the mechanisms by which signals are transduced from the activated cell surface neurotrophin receptors to the microtubule networks through a Cdk5-Axin-GSK-3 $\beta$-dependent pathway during axon formation (Fig. $8 E$ ).

Axon formation is controlled by extracellular ligands and intrinsic programs (Arimura and Kaibuchi, 2007). Extensive studies have focused on characterizing the pathways for polarized axonal growth in cultured neuronal systems; however, the functional roles of these signaling pathways in vivo remain unclear. Among these, only LKB1 and Tsc-mediated signaling cascades, which regulate either the activity or the level of SAD kinase in response to BDNF, have been shown to regulate axon formation in vivo (Kishi et al., 2005; Barnes et al., 2007; Shelly et al., 2007; Choi et al., 2008; Wildonger et al., 2008). Our findings add Cdk5Axin-GSK- $3 \beta$ signaling to the list of pathways that are important for axon formation in vivo. Blocking the Cdk5-dependent phosphorylation of Axin alone is sufficient to prevent direct interaction between Axin and GSK- $3 \beta$ and inactivation of GSK-3 $\beta$. Our data therefore suggest that phosphorylation of Axin by Cdk5

$\leftarrow$

(Figure legend continued.) Student's $t$ test, mean \pm SEM. $\boldsymbol{H}, \boldsymbol{I}$, Phosphorylation of Axin at Thr485 is essential for axon formation in cultured hippocampal neurons. Whereas expression of shRNA-resistant Axin restored axon formation in Axin-deficient neurons, Axin-T485A failed to rescue axon formation. The arrow indicated the axon; arrowheads indicated non-axonal neurites. Scale bar, $20 \mu \mathrm{m}$. More than 300 neurons were examined and quantified for each condition. ${ }^{*} p<0.05,{ }^{* *} p<0.01, n=3$, one-way ANOVA, mean \pm SEM. for axon formation.

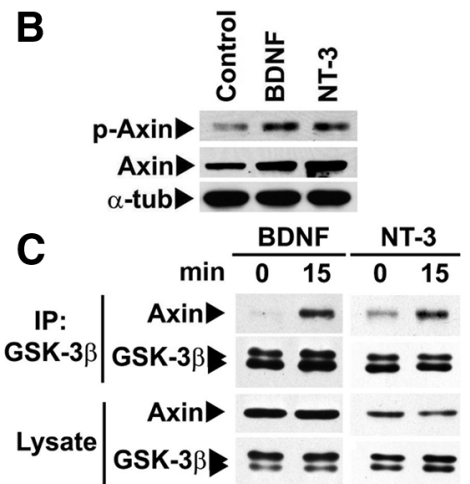

E

Polarized extracellular cues (BDNF, NT-3?)

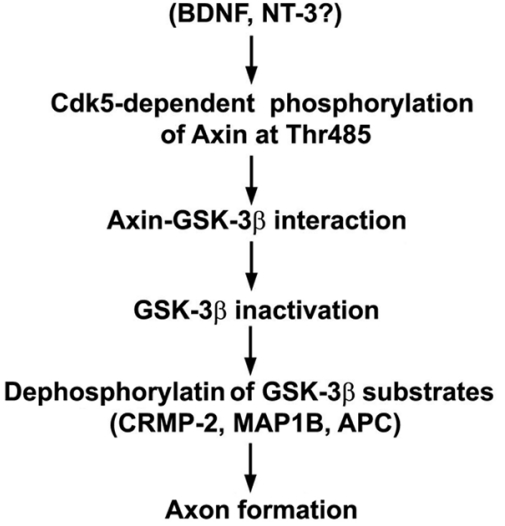

Axon formation

Figure 8. Axin phosphorylation by Cdk5 mediates the neurotrophin-stimulated GSK-3 $\beta$ inhibition through Axin-GSK-3 $\beta$

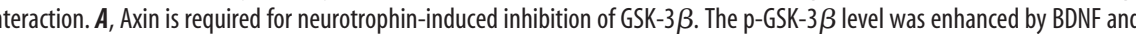

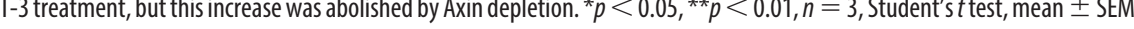
SK-3 $\beta$-dependent microtubule dynamics during axon formation. Although basal interaction of Axin and GSK-3 $\beta$ can be detected in neurons, this specific interaction increases significantly in a $\mathrm{Cdk5}$-dependent manner upon stimulation with neurotrophins, regulation of GSK-3 $\beta$ activity and reduced phosphorylation of GSK-3 $\beta$ downstream effectors (such as (RMP-2) that are important

serves as a switch to turn off GSK-3 $\beta$ during axon formation. It is interesting to speculate that the Axin phosphorylation-dependent recruitment of GSK-3 $\beta$ to Axin allows GSK-3 $\beta$ to get into close proximity to its immediate upstream kinases, aPKC or Akt, for the inhibitory phosphorylation. Consistent with this notion, it was reported that Akt binds to Axin-GSK- $3 \beta$ complex and phosphorylates GSK-3 $\beta$ at Ser9 in PC12 neuronal cells (Fukumoto et al., 2001). Our results reveal a new regulatory mechanism of GSK-3 $\beta$ inhibition through posttranslational modification of its scaffold protein Axin.

The Cdk5 phosphorylation site is located at Thr485 on Axin, which is adjacent to the GSK- $3 \beta$-binding domain of Axin (amino acids 353-437). Whether phosphorylation of Axin at this site changes the conformation of the GSK-3 $\beta$-binding domain of Axin and facilitates its interaction with GSK- $3 \beta$ in neurons awaits additional studies. Whereas $\mathrm{Cdk} 5$ has been previously implicated in the regulation of GSK- $3 \beta$ activity, the underlying mechanisms remain unclear (Plattner et al., 2006; Wen et al., 2008). Blockade of Cdk 5 prevents inhibitory phosphorylation of GSK-3 $\beta$ at Ser9, whereas overexpression of the Cdk5 activator p 25 in young mice inactivates GSK- $3 \beta$ through phosphorylation at Ser9. Our results provide a possible mechanism that Cdk5 inactivates GSK-3 $\beta$ in 
vivo through phosphorylating Axin and enhancing interaction of Axin-GSK-3 $\beta$. Thus, our findings provide a new direction for future studies on the crosstalk and interplay between $\mathrm{Cdk} 5$ and GSK-3 $\beta$ during neuronal development.

GSK- $3 \beta$ has been implicated as the master negative regulator of axon formation (Hur and Zhou, 2010). Moderate inhibition of GSK-3 $\beta$ is important for axon formation in cultured neurons (Zhou et al., 2004; Jiang et al., 2005), although perturbing the inhibitory phosphorylation of GSK-3 $\beta$ at Ser-9 alone is not sufficient to affect the establishment of axons in vivo (Gärtner et al., 2006). Our findings reveal that Cdk5-mediated phosphorylation of Axin leads to inactivation of GSK-3 $\beta$, which in turn results in dephosphorylation of CRMP-2 at Thr514. The dephosphorylation of CRMP-2 is suggested to facilitate its association with tubulin heterodimers and maintain the microtubule assembly during axon formation (Fukata et al., 2002). Intriguingly, in addition to its negative regulation of GSK- $3 \beta$, Cdk5 acts as a priming kinase for GSK- $3 \beta$-mediated phosphorylation of CRMP-2 (Cole et al., 2006). Phosphorylation by Cdk5 at Ser522 primes CRMP-2 to the GSK-3 $\beta$-mediated phosphorylation at Thr518 and Thr514 (Yoshimura et al., 2005; Cole et al., 2006). The Cdk5/ Axin-dependent inhibitory control of GSK- $3 \beta$ may thus serve as an important mechanism for regulating CRMP-2 phosphorylation (e.g., to prevent excessive phosphorylation of CRMP-2 by GSK-3 $\beta$ ). Similar regulatory mechanism has been proposed for the regulation of Tau phosphorylation by Cdk5 and GSK-3 $\beta$ in young mice (Plattner et al., 2006). The Cdk5/Axin-dependent inactivation of GSK-3 $\beta$ may also lead to reduced phosphorylation of other microtubule-associated proteins such as APC, Tau, and MAP1B. Indeed, Axin inhibits GSK-3 $\beta$-dependent Tau phosphorylation in mammalian cells (Stoothoff et al., 2002). Together, Axin phosphorylation by Cdk5 may serve as a modulator to avoid excessive phosphorylation of GSK-3 $\beta$ substrates, thereby maintaining the stability of the microtubules.

In this study, we show that Cdk5-dependent phosphorylation of Axin is involved in the neurotrophin-dependent inactivation of GSK-3 $\beta$. BDNF has been well characterized to activate the PI3K/Akt signaling, which then phosphorylates GSK-3 $\beta$ at Ser9 and inactivates the kinase (Yoshimura et al., 2005). BDNF also increases Cdk5 activity (Cheung et al., 2007), through the PKC $\delta$ mediated stabilization of Cdk5 activator p35 (Zhao et al., 2009), or tyrosine phosphorylation of Cdk5 (Sasaki et al., 2002). Here, we report that Cdk5-dependent phosphorylation of Axin mediates the BDNF-induced inhibition of GSK-3 $\beta$, hinting at a possible interplay between Cdk5/Axin and PI3K/Akt pathway in neurons. Other than BDNF, transforming growth factor $\beta$ (TGF- $\beta$ ) was recently demonstrated to specify axon formation during brain development (Yi et al., 2010). Interestingly, Axin is a scaffold protein in the TGF- $\beta$ signaling (Liu et al., 2006). Thus, it will be interesting to examine whether Cdk5/Axin signaling mediates TGF- $\beta$ signaling in axon development.

Given that aberrant hyperactivation of GSK- $3 \beta$ is associated with various psychiatric disorders and neurodegenerative diseases, it will be interesting to explore the potential involvement of Cdk5/Axin signaling in the dysregulation of GSK-3 $\beta$ signaling. Whereas inhibitors of GSK- $3 \beta$ have been widely used for the treatment of various nervous system disorders, many of them target the ATP-binding pocket of GSK- $3 \beta$, resulting in side effects (Meijer et al., 2004). Our findings provide in vivo evidence that the Cdk5-dependent phosphorylation or direct interaction of Axin with GSK-3 $\beta$ is crucial for the inactivation of GSK-3 $\beta$. Thus, additional studies on the regulation of Cdk5-dependent Axin phosphorylation or its interaction with GSK- $3 \beta$ will be im- portant for providing insights into the pathophysiological mechanisms underlying these disorders.

\section{References}

Arimura N, Kaibuchi K (2007) Neuronal polarity: from extracellular signals to intracellular mechanisms. Nat Rev Neurosci 8:194-205.

Barnes AP, Lilley BN, Pan YA, Plummer LJ, Powell AW, Raines AN, Sanes JR, Polleux F (2007) LKB1 and SAD kinases define a pathway required for the polarization of cortical neurons. Cell 129:549-563.

Bradke F, Dotti CG (1999) The role of local actin instability in axon formation. Science 283:1931-1934.

Cáceres A, Banker GA, Binder L (1986) Immunocytochemical localization of tubulin and microtubule-associated protein 2 during the development of hippocampal neurons in culture. J Neurosci 6:714-722.

Carl M, Bianco IH, Bajoghli B, Aghaallaei N, Czerny T, Wilson SW (2007) Wnt/Axin1/beta-catenin signaling regulates asymmetric nodal activation, elaboration, and concordance of CNS asymmetries. Neuron 55:393-405.

Cheung ZH, Chin WH, Chen Y, Ng YP, Ip NY (2007) Cdk5 is involved in BDNF-stimulated dendritic growth in hippocampal neurons. PLoS Biol 5:e63.

Choi YJ, Di Nardo A, Kramvis I, Meikle L, Kwiatkowski DJ, Sahin M, He X (2008) Tuberous sclerosis complex proteins control axon formation. Genes Dev 22:2485-2495.

Ciani L, Krylova O, Smalley MJ, Dale TC, Salinas PC (2004) A divergent canonical WNT-signaling pathway regulates microtubule dynamics: dishevelled signals locally to stabilize microtubules. J Cell Biol 164:243-253.

Cole AR, Causeret F, Yadirgi G, Hastie CJ, McLauchlan H, McManus EJ, Hernández F, Eickholt BJ, Nikolic M, Sutherland C (2006) Distinct priming kinases contribute to differential regulation of collapsin response mediator proteins by glycogen synthase kinase-3 in vivo. J Biol Chem 281:16591-16598.

Conde C, Cáceres A (2009) Microtubule assembly, organization and dynamics in axons and dendrites. Nat Rev Neurosci 10:319-332.

Cong F, Varmus H (2004) Nuclear-cytoplasmic shuttling of Axin regulates subcellular localization of beta-catenin. Proc Natl Acad Sci USA 101:2882-2887.

Connell-Crowley L, Le Gall M, Vo DJ, Giniger E (2000) The cyclindependent kinase $\mathrm{Cdk} 5$ controls multiple aspects of axon patterning in vivo. Curr Biol 10:599-602.

Dotti CG, Sullivan CA, Banker GA (1988) The establishment of polarity by hippocampal neurons in culture. J Neurosci 8:1454-1468.

Engmann O, Giese KP (2009) Crosstalk between Cdk5 and GSK3beta: Implications for Alzheimer's Disease. Front Mol Neurosci 2:2.

Etienne-Manneville S, Hall A (2003) Cdc42 regulates GSK-3beta and adenomatous polyposis coli to control cell polarity. Nature 421:753-756.

Fletcher TL, Cameron P, De Camilli P, Banker G (1991) The distribution of synapsin I and synaptophysin in hippocampal neurons developing in culture. J Neurosci 11:1617-1626.

Fu WY, Chen Y, Sahin M, Zhao XS, Shi L, Bikoff JB, Lai KO, Yung WH, Fu AK, Greenberg ME, Ip NY (2007) Cdk5 regulates EphA4-mediated dendritic spine retraction through an ephexin1-dependent mechanism. Nat Neurosci 10:67-76.

Fujimori KE, Takeuchi K, Yazaki T, Uyemura K, Nojyo Y, Tamamki N (2000) Expression of L1 and TAG-1 in the corticospinal, callosal, and hippocampal commissural neurons in the developing rat telencephalon as revealed by retrograde and in situ hybridization double labeling. J Comp Neurol 417:275-288.

Fukata Y, Itoh TJ, Kimura T, Ménager C, Nishimura T, Shiromizu T, Watanabe H, Inagaki N, Iwamatsu A, Hotani H, Kaibuchi K (2002) CRMP-2 binds to tubulin heterodimers to promote microtubule assembly. Nat Cell Biol 4:583-591.

Fukumoto S, Hsieh CM, Maemura K, Layne MD, Yet SF, Lee KH, Matsui T, Rosenzweig A, Taylor WG, Rubin JS, Perrella MA, Lee ME (2001) Akt participation in the Wnt signaling pathway through Dishevelled. J Biol Chem 276:17479-17483.

Gärtner A, Huang X, Hall A (2006) Neuronal polarity is regulated by glycogen synthase kinase-3 (GSK-3beta) independently of Akt/PKB serine phosphorylation. J Cell Sci 119:3927-3934.

Heisenberg CP, Houart C, Take-Uchi M, Rauch GJ, Young N, Coutinho P, Masai I, Caneparo L, Concha ML, Geisler R, Dale TC, Wilson SW, Stemple DL (2001) A mutation in the Gsk3-binding domain of zebrafish 
Masterblind/Axin1 leads to a fate transformation of telencephalon and eyes to diencephalon. Genes Dev 15:1427-1434.

Hur EM, Zhou FQ (2010) GSK3 signalling in neural development. Nat Rev Neurosci 11:539-551.

Ikeda S, Kishida S, Yamamoto H, Murai H, Koyama S, Kikuchi A (1998) Axin, a negative regulator of the Wnt signaling pathway, forms a complex with GSK-3beta and beta-catenin and promotes GSK-3beta-dependent phosphorylation of beta-catenin. EMBO J 17:1371-1384.

Inagaki N, Chihara K, Arimura N, Ménager C, Kawano Y, Matsuo N, Nishimura T, Amano M, Kaibuchi K (2001) CRMP-2 induces axons in cultured hippocampal neurons. Nat Neurosci 4:781-782.

Jiang H, Guo W, Liang X, Rao Y (2005) Both the establishment and the maintenance of neuronal polarity require active mechanisms: critical roles of GSK-3beta and its upstream regulators. Cell 120:123-135.

Kaech S, Banker G (2006) Culturing hippocampal neurons. Nat Protoc 1:2406-2415.

Kikuchi A (1999) Roles of Axin in the Wnt signalling pathway. Cell Signal 11:777-788.

Kim WY, Zhou FQ, Zhou J, Yokota Y, Wang YM, Yoshimura T, Kaibuchi K, Woodgett JR, Anton ES, Snider WD (2006) Essential roles for GSK-3s and GSK-3-primed substrates in neurotrophin-induced and hippocampal axon growth. Neuron 52:981-996.

Kishi M, Pan YA, Crump JG, Sanes JR (2005) Mammalian SAD kinases are required for neuronal polarization. Science 307:929-932.

Kwon YT, Tsai LH, Crandall JE (1999) Callosal axon guidance defects in p35(-/-) mice. J Comp Neurol 415:218-229.

Liu W, Rui H, Wang J, Lin S, He Y, Chen M, Li Q, Ye Z, Zhang S, Chan SC, Chen YG, Han J, Lin SC (2006) Axin is a scaffold protein in TGF-beta signaling that promotes degradation of Smad7 by Arkadia. EMBO J 25:1646-1658.

Mandelkow EM, Biernat J, Drewes G, Gustke N, Trinczek B, Mandelkow E (1995) Tau domains, phosphorylation, and interactions with microtubules. Neurobiol Aging 16:355-362; discussion 362-363.

Mandell JW, Banker GA (1996) A spatial gradient of tau protein phosphorylation in nascent axons. J Neurosci 16:5727-5740.

Mandell JW, Banker GA (1995) The microtubule cytoskeleton and the development of neuronal polarity. Neurobiol Aging 16:229-237; discussion 238.

Meijer L, Flajolet M, Greengard P (2004) Pharmacological inhibitors of glycogen synthase kinase 3. Trends Pharmacol Sci 25:471-480.

Morfini G, Szebenyi G, Brown H, Pant HC, Pigino G, DeBoer S, Beffert U, Brady ST (2004) A novel CDK5-dependent pathway for regulating GSK3 activity and kinesin-driven motility in neurons. EMBO J 23:2235-2245.

Paglini G, Pigino G, Kunda P, Morfini G, Maccioni R, Quiroga S, Ferreira A, Cáceres A (1998) Evidence for the participation of the neuron-specific CDK5 activator p35 during laminin-enhanced axonal growth. J Neurosci 18:9858-9869.

Perry WL 3rd, Vasicek TJ, Lee JJ, Rossi JM, Zeng L, Zhang T, Tilghman SM, Costantini F (1995) Phenotypic and molecular analysis of a transgenic insertional allele of the mouse Fused locus. Genetics 141:321-332.

Plattner F, Angelo M, Giese KP (2006) The roles of cyclin-dependent kinase 5 and glycogen synthase kinase 3 in tau hyperphosphorylation. J Biol Chem 281:25457-25465.

Rui Y, Xu Z, Xiong B, Cao Y, Lin S, Zhang M, Chan SC, Luo W, Han Y, Lu Z,
Ye Z, Zhou HM, Han J, Meng A, Lin SC (2007) A beta-cateninindependent dorsalization pathway activated by Axin/JNK signaling and antagonized by aida. Dev Cell 13:268-282.

Saito T (2006) In vivo electroporation in the embryonic mouse central nervous system. Nat Protoc 1:1552-1558.

Sasaki Y, Cheng C, Uchida Y, Nakajima O, Ohshima T, Yagi T, Taniguchi M, Nakayama T, Kishida R, Kudo Y, Ohno S, Nakamura F, Goshima Y (2002) Fyn and Cdk5 mediate semaphorin-3A signaling, which is involved in regulation of dendrite orientation in cerebral cortex. Neuron 35:907-920.

Shelly M, Cancedda L, Heilshorn S, Sumbre G, Poo MM (2007) LKB1/ STRAD promotes axon initiation during neuronal polarization. Cell 129:565-577.

Smalley MJ, Sara E, Paterson H, Naylor S, Cook D, Jayatilake H, Fryer LG, Hutchinson L, Fry MJ, Dale TC (1999) Interaction of axin and Dvl-2 proteins regulates Dvl-2-stimulated TCF-dependent transcription. EMBO J 18:2823-2835.

Smith D (2003) Cdk5 in neuroskeletal dynamics. Neurosignals 12:239-251.

Smith DS, Tsai LH (2002) Cdk5 behind the wheel: a role in trafficking and transport? Trends Cell Biol 12:28-36.

StoothoffWH, Bailey CD, Mi K, Lin SC, Johnson GV (2002) Axin negatively affects tau phosphorylation by glycogen synthase kinase 3beta. J Neurochem 83:904-913.

Ulfig N, Nickel J, Bohl J (1998) Monoclonal antibodies SMI 311 and SMI 312 as tools to investigate the maturation of nerve cells and axonal patterns in human fetal brain. Cell Tissue Res 291:433-443.

Wen Y, Planel E, Herman M, Figueroa HY, Wang L, Liu L, Lau LF, Yu WH, Duff KE (2008) Interplay between cyclin-dependent kinase 5 and glycogen synthase kinase $3 \beta$ mediated by neuregulin signaling leads to differential effects on tau phosphorylation and amyloid precursor protein processing. J Neurosci 28:2624-2632.

Wiechens N, Heinle K, Englmeier L, Schohl A, Fagotto F (2004) Nucleocytoplasmic shuttling of Axin, a negative regulator of the Wnt-betacatenin Pathway. J Biol Chem 279:5263-5267.

Wildonger J, Jan LY, Jan YN (2008) The Tsc1-Tsc2 complex influences neuronal polarity by modulating TORC1 activity and SAD levels. Genes Dev 22:2447-2453.

Witte H, Bradke F (2008) The role of the cytoskeleton during neuronal polarization. Curr Opin Neurobiol 18:479-487.

Witte H, Neukirchen D, Bradke F (2008) Microtubule stabilization specifies initial neuronal polarization. J Cell Biol 180:619-632.

Yi JJ, Barnes AP, Hand R, Polleux F, Ehlers MD (2010) TGF-beta signaling specifies axons during brain development. Cell 142:144-157.

Yoshimura T, Kawano Y, Arimura N, Kawabata S, Kikuchi A, Kaibuchi K (2005) GSK-3 beta regulates phosphorylation of CRMP-2 and neuronal polarity. Cell 120:137-149.

Yoshimura T, Arimura N, Kawano Y, Kawabata S, Wang S, Kaibuchi K (2006) Ras regulates neuronal polarity via the PI3-kinase/Akt/GSK3beta/CRMP-2 pathway. Biochem Biophys Res Commun 340:62-68.

Zhao CT, Li K, Li JT, Zheng W, Liang XJ, Geng AQ, Li N, Yuan XB (2009) PKC delta regulates cortical radial migration by stabilizing the Cdk5 activator p35. Proc Natl Acad Sci U S A 106:21353-21358.

Zhou FQ, Zhou J, Dedhar S, Wu YH, Snider WD (2004) NGF-induced axon growth is mediated by localized inactivation of GSK-3beta and functions of the microtubule plus end binding protein APC. Neuron 42:897-912. 